\title{
Reductive or oxidative catalytic lignin depolymerization: An overview of recent advances
}

\author{
Dolorès Bourbiaux, Junjie Pu, Franck Rataboul, Laurent Djakovitch *, Christophe Geantet, \\ Dorothée Laurenti*
}

Univ. Lyon, Université Claude Bernard Lyon 1, CNRS, IRCELYON, F-69626, Villeurbanne, France

\section{A R T I C L E I N F O}

Keywords:

Biorefinery

Ca talysis

Solvent effect

Monomers

Bio-based platform chemicals

\begin{abstract}
A B S T R A C T
Lignin, one of the main biopolymers in lignocellulosic biomass, is a promising feed stock for producing aromatic chemicals and BTX-fuels. Despite high availability, lignin remains under-valorized to chemical formation motivating research towards upgrading through depolymerization. Catalytic approaches are particularly studied since they can influence the selectivity of depolymerization. Next to thermal or acid/base depolymerization, catalytic routes under either oxidative or reductive atmosphere represent a very attractive way to produce aromatics for fine chem istry and energy. This literature overview shows that the depolymerization outcome depends strongly on the reaction conditions. While under oxidative atmosphere highly functionalized high-added value chemicals like vanillin are obtained, alkylphenolics and BTX are mainly observed when conducting the reaction under reductive atmosphere. Additionally, results depend mainly on the nature of the catalyst for the former approach, whereas reaction conditions play an essential role when operating under hydrogen. Understanding and comparing these quite complex methodologies over the last ten years constitutes the focus of this review.
\end{abstract}

\section{Introduction}

Lignocellulosic biomass is a well-known promising feedstock to ensure the production of renewable chemicals and fuels for the future replacing at least partially the fossil resources. Lignin is one of the major components of this lignocellulosic biomass. Despite the fact that lignin can be produced at high scale from the pulp and paper industries, it is currently underutilized for the production of chemicals. One interesting valorization is the depolymerization of lignin to provide aromatic platform chemicals. Indeed, lignin is the only abundant polymer constituted of aromatic moieties and represents therefore a natural resource for a biosourced production of aromatic molecules. It is well known that lignin obtained after lignocellulose frag mentation is drastically modified compared to the "native" lignin initially present within the biomass [1]. These modifications, especially through condensation reactions (i.e. formation of $\mathrm{C}-\mathrm{C}$ bonds), produce a "technical" lignin more robust towa rds depolymerization. A general structure of lignin is presented in Fig. 1 showing the heterogeneity of the constituting monomeric components and of the primary linkag es forming the polymeric network. Nevertheless, some tendencies exist depending on the lignin origin. Guaïacyl units are mainly found in softwood with $p$ - hydroxyphenyl in lower proportion while hardwood contains also syringyl units. For both types of wood, the dominant inter-aromatic linkage is the so-called $\beta$-O-4.

Considering lignin valorization, catalysis is taking a predominant place since it can promote lignin depolymerization through different routes leading to different product families and, in the general context of biomass valorization, is currently the subject of intensive studies [2]. Depolymerization of lignin can be performed via various processes, enzymatic, thermal and catalytic and the operating conditions greatly impact the composition and yield of products. For instance, depolymerization can be performed in the presence of acid-base catalysts, or with metal catalysts under oxidative or reductive conditions. Oxidative processes have the advantage to give access in a green manner to highvalue functionalized chemicals while reductive depolymerization leads generally to higher quantity of monomers, including deoxygenated products like BTX (benzene, toluene, xylenes) which are of interest as platform molecules. Here the heterogeneity of the polymer structure may have an impact on the selectivity of linkage cleavage and consequently on selectivity of monomeric products. Since the first comprehensive literature review from Weckhuysen and coworkers [2], numerous review papers have appeared covering general aspects of the cat-

\footnotetext{
* Correspond ing authors.

E-mail addresses: laurent.djakovitch@ircelyon.univ-lyon1.fr (L. Djakovitch), dorothee.laurenti@ircelyon.univ-lyon1.fr (D. Laurenti).
} 


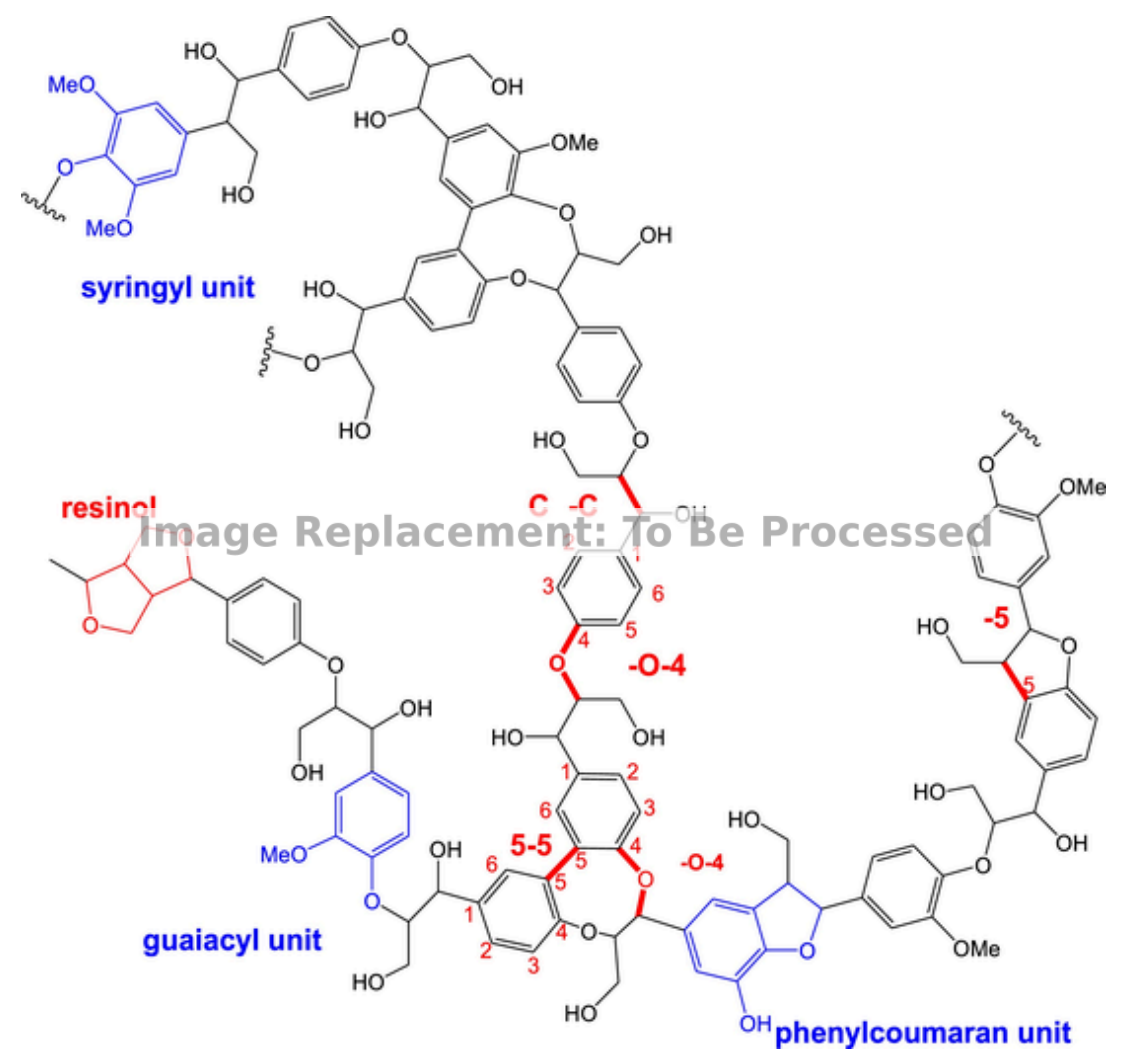

Fig. 1. Schematic representation of lignin with some examples of the main fragments types and bonds.

alytic transformation of lignin highlighting the research efforts that are currently performed in this field [3-11]. All general information concerning lignin origins, isolation, structures, current uses, and possible valorization methods are also available through this literature. For example a recent review article from Rinaldi and coworkers presents many aspects of lignin valorization from the beginning-to-end, reporting the recent advances made on the biosynthesis aspects to the valorization including the recent "lignin-first" approach [12]. Effectively, in order to circumvent the lignin modification after usual frag mentation processes, many authors propose new fractionation technologies to preserve the native lignin structure and facilita te the catalytic conversion to functionalized monomers [13,14]. Even if those technologies are very promising and efficient, the valorization of a great part of coproduced lignin in biorefineries or pulp industry targeted to cellulose exploitation is still highly desirable. The present review intends to focus on two distinct routes of catalytic lignin depolymerization under oxidative and reductive conditions. The aim is to present recent advances obtained by the use of heterogeneous and reusable catalysts on lignin giving monomers. This excludes studies on lignin models that will be discussed only if pertinent. It will first detail the oxidative depolymerization, then the reductive depolymerization. The transformations will be described depending on the specific tendencies for each. For example, it appears that for oxidative depolymerization the type of catalyst plays a major role and a wide diversity of catalysts have been assessed. For reductive depolymerization, the catalytic systems are less varied while the operating conditions are clearly crucial.

\section{Catalytic oxidative depolymerization of lignin}

Several review articles already cover some of the work realized in almost all fields of this transformation route and the reader is invited to consult these reviews either for a general landscape or for precise points concerning a specific technology [15-27]. As introduced above, the present review intends to focus on works dealing with heterogeneous or recoverable catalysis approaches trying to describe the relationships between the lignin and the catalyst. Additionally, despite the fact that a variety of oxidants are used, only those using oxygen as the oxidant will be discussed here, either pure or diluted in nitrogen including air, to highlight the green chemistry context. Moreover, as for the reductive depolymerization, the majority of articles concerning oxidative depolymerization deals with molecular lignin models presenting the most widely occurring bonds like the $\beta-O-4$ linkage. Here, this review addresses the literature dealing with technical lignin transformation that reports key qualitative and quantitative data to support the experimental observations. In addition, a few reports were included given their "innovative" approach. Various type of catalysts were proposed for the oxidative depolymerization of lignin and this part will describe the reactivity of lignin with these different catalysts.

\subsection{Polyoxometallates}

Polyoxometallates (POMS) are well known catalysts for oxidation reactions, especially those based on molybdenum or vanadium metals. POMS have been used as oxidation catalysts in delignification for producing pulp in the paper industry since the $90 \mathrm{~s}$; however, reports addressing their potential to produce chemicals from lignin are rather recent. In 2008, Rohr and co-workers demonstrated that POMs are effective oxidation catalysts for converting Indulin Kraft lignin into aromatics, mainly vanillin. Note that there was no mention of the effect of the acid features of the POMs on these transformations. Treating Indulin in a $\mathrm{MeOH}-\mathrm{H}_{2} \mathrm{O}(4: 1)$ mixture at $170{ }^{\circ} \mathrm{C}$ under $\mathrm{O}_{2}$ (10 bar) with $\mathrm{H}_{3} \mathrm{PMo}_{12} \mathrm{O}_{40}$, authors reported a $70 \%$ conversion of initial lignin to extractibles in $\mathrm{CHCl}_{3}$ (ca. $65 \%$ ), $5 \%$ wt being lost as gas products (Scheme $1)$. Interestingly, the authors reported some characterization of extractibles that contain, when stabilized (see below) $7 \%$ wt (vanillin and methylvanillate) in a 1:1 ratio (from esterification of vanillic acid under the reaction conditions) and oligomeric compounds that represent an average molecular weight $\mathrm{M}_{\mathrm{w}}=1860 \mathrm{~g} \cdot \mathrm{mol}^{-1}$, much lower than 


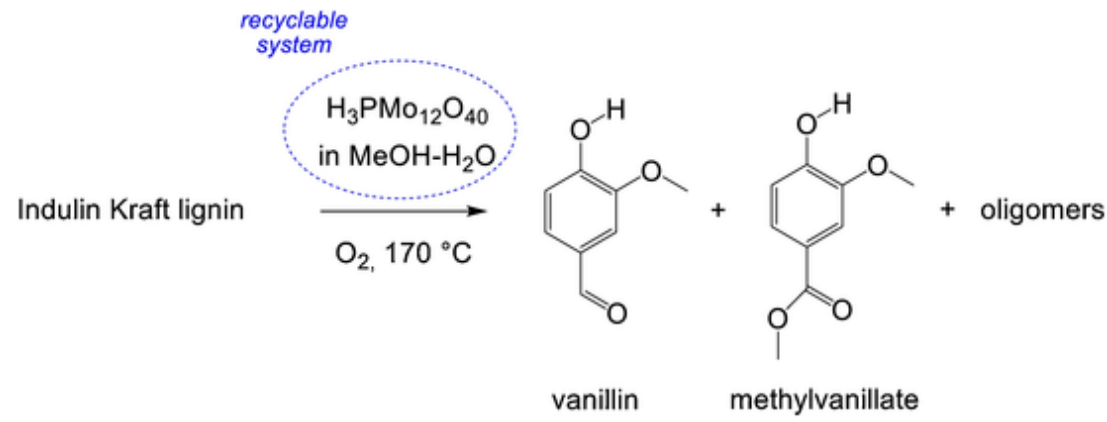

Scheme 1. Lignin oxidative depolymerization with polyoxometallates in methanol.

that of initial lignin $\left(\mathrm{M}_{\mathrm{w}}=4120 \mathrm{~g} \cdot \mathrm{mol}^{-1}\right)$. Therefore, significant reduction of $\mathrm{M}_{\mathrm{w}}$ wa s observed [28]. Very interesting in this report is the reuse of the catalytic reaction medium recovered af ter filtration of remaining lignin and extraction of products. Despite the fact that some catalyst was found in the solid products, the recovered medium showed constant activity providing constant yields since the second run. From a process view, it was noticed that a slight increase in vanillin and methylvanillate yields attributed to incomplete extraction of the aromatic compounds after catalytic run enhancing thus observed yield in following runs. Slight deactivation was observed in the 7th run, which was solved by adding sulfuric acid to restore initial acidic conditions. In fact, while the $\mathrm{pH}$ of aqueous solution of indulin was given as 10.5 by the supplier, it decreased to 1.13 after addition of the aqueous solution of POM catalyst.

Following this report, Zhao et al. reported the depolymerization of various lignins using $\mathrm{H}_{5} \mathrm{PMo}_{10} \mathrm{~V}_{2} \mathrm{O}_{40}$ as catalyst under conditions, once optimized, similar to those described by van Rohr and coworkers $\left(190{ }^{\circ} \mathrm{C}, \mathrm{MeOH}-\mathrm{H}_{2} \mathrm{O}\right.$ 9:1), $\mathrm{pH}$ of reaction mixture 0.93, $\mathrm{O}_{2} 20$ bar [29]. Five lignins were studied varying from the nature of the extraction process, i.e. pyrolytic (PL), hydrolytic (HL) (from $\mathrm{HCl}$ process), alkali (AK), lignosulfonate as sodium (LS) or calcium (LC) salts, and probably that of the botanic origin. Therefore, these lignins differed in term of molecular weight $\left(\mathrm{M}_{\mathrm{w}}\right.$ from 1047 to $\left.60.000 \mathrm{~g} \cdot \mathrm{mol}^{-1}\right)$ and degree of polymerization (DP) of constitutive C9-phenylpropyl units (DP from 6 to 400). Initial studies were conducted in a different solvent mixture $\mathrm{MeOH}-\mathrm{H}_{2} \mathrm{O}$ 1:9. While the efficiency of the catalyst depends on the reaction temperature $\left(150-210^{\circ} \mathrm{C}\right)$ and the solvent mixture, an optimum was observed at $190{ }^{\circ} \mathrm{C}$. At this temperature, the authors argued that $\mathrm{M}_{\mathrm{w}}$ and DP played an important role in terms of oily product yields. Pyrolytic lignin having the lower values $\left(\mathrm{M}_{\mathrm{w}} / \mathrm{DP} 1047 / 6\right)$ gave also the highest yield of $15.2 \%$. Other lignins gave yields between ca. $5 \%$ (AL, 60.000/400) and ca. $17 \%$ (HL, 45.000/300) (SL and CL gave resp. ca. $12 \%$ and $8 \%$; resp. 52.000/350 and 18.000/120). From these data, effects of $\mathrm{M}_{\mathrm{w}}$ and DP are obvious suggesting that other factors, like $\mathrm{S} / \mathrm{G} /$ $\mathrm{H}$ ratio, influence also the production of oily compounds. The main impact on efficiency was revealed when addressing the effect of solvent mixture ratio. Increasing the content of methanol, yields of oily compounds reached for PL $47 \%$ in a mixture $\mathrm{MeOH}-\mathrm{H}_{2} \mathrm{O}$ 9:1. Authors attributed this effect to the role of methanol as promoter of the oxidation through radical formation and its role as capping agent preventing degradations or recondensations. Here also efficient reuse of the cata- lyst was possible by recovering the product-free reaction medium up to 5 cycles, confirming the stability of POMS catalysts under these conditions. However, methanol was described in other works related to lignin depolymerization to give higher alcohols and alkylation products thus increasing the yields of oily fractions [30,31]. This assumption is supported by studying the composition of the oily fraction that contains, like in the work reported by van Rohr and coworkers, aromatic compounds such as aldehydes, carboxylic esters (methanol derived from) along with diesters from methanol issued from over oxidation of the aromatic products. Unfortunately, no quantitative data were given for each compound preventing estimation of the presence or not of higher alcohol products. Another recent report concerns the oxidative depolymerization of alkali lignin comparing tungsten- or molybdenum-based POMs. Reactions were conducted between 175 and $225{ }^{\circ} \mathrm{C}$. Whatever the catalysts, carboxylic acids such as formic, acetic and succinic were the main products observed attesting for an over oxidation of the intermediate aromatic compounds derived from lignin depolymerization (Scheme 2) [32]. Generally, best results were observed at $200{ }^{\circ} \mathrm{C}$, with both catalysts, especially with the molybdenum-based POM that proved to be more selective giving $95 \%$ lignin conversion and ca. $45 \%$ total yield of carboxylic acids. Catalyst recovery wa s possible using gravimetric procedures by addition of $\mathrm{Et}_{2} \mathrm{O}$ forming a POMether complex for $\mathrm{H}_{3} \mathrm{PW}_{12} \mathrm{O}_{40}$, or by simple distillation of the reaction mixture for $\mathrm{H}_{3} \mathrm{PMo}_{12} \mathrm{O}_{40}$. Noteworthy, in this report the authors did not observe, nor report, the presence of aromatic compounds like vanillin or vanillic acid. This can be rationalized by comparing the applied reaction conditions. In this work all reactions were conducted in pure water, whereas in previously described studies alcohols were used as cosolvent, confirming therefore their role to prevent degradation reactions (i.e. over oxidation). This provides some indications for developing further lignin depolymerization with such highly active oxidation catalysts depending on the targeted compounds.

\subsection{Perovskites}

Perovskites of general formulae $\mathrm{ABO}_{3}$ or alternatively, $\mathrm{AB}_{1-\mathrm{x}} \mathrm{D}_{\mathrm{x}} \mathrm{O}_{3}$ (with $\mathrm{A}=\mathrm{La}, \mathrm{B}=\mathrm{Mn}, \mathrm{Co}, \mathrm{Fe}, \mathrm{D}=\mathrm{Cu} \ldots$ ), are a well-established class of catalysts for hydrocarbons oxidation due to the redox behavior of the $\mathrm{B}$ and $\mathrm{D}$ metals. Their use as catalysts in oxidative depolymerization of lignin is rather recent, and wa s mostly developed by Lin and Liu and coworkers [33-35] following the pioneering works of Yang et al.

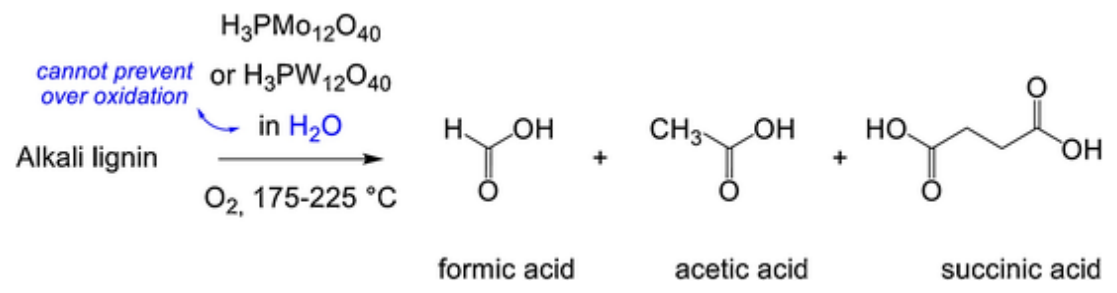

Scheme 2. Lignin oxidative depolymerization with polyoxometallates in water. 
[36] and Royer et al. [37]. Authors evaluated various perovskites for oxidative depolymerization of enzymatic extracted lignin from steamexploded cornstalk (Table 1).

Data reported in Table 1 show that perovskite catalysts improve both lignin conversion and production of aromatics. As expected, best results were obtained with catalysts containing $\mathrm{Cu}$. Thus with $\mathrm{LaFe}_{0.8} \mathrm{Cu}_{0.2} \mathrm{O}_{3} 65 \%$ of conversion was observed (Scheme 3 ). Respective yields of aldehydes probably reflect the original composition of lignin used; that is linked to $\mathrm{S} / \mathrm{G} / \mathrm{H}$ ratio (not given here) and the facility to break corresponding bonds. Nevertheless, for each analyzed aldehyde, an increase of the yields was observed in the presence of catalyst, those containing $\mathrm{Cu}$ exhibiting the highest yields. However, yields of vanillin and syringaldehyde decreased after a relatively short reaction time $(0.5-1 \mathrm{~h})$ that was at tributed to over oxidation to organic acids.

Although difficult to assess, XPS studies support a possible mechanism involving formation of redox metallic couples by adsorption of oxygen species at the surface of the perovskites. The efficiency may be related to the good oxygen storage capacities of such materials. Efficient reusability up to 5 cycles was demonstrated with all catalysts which were reengaged without specific treatment af ter a simple filtration and no structural nor textural changes were observed during the lignin oxidative depolymerization procedures.

\subsection{Metal oxides}

Metal oxides are common oxidation catalysts. For lignin oxidative depolymerization, besides rhenium oxides and associated $\mathrm{MeReO}_{3}$ $[27,38], \mathrm{CuO}$ is probably the most documented catalyst [39]. Good activity can be reached, but generally the selectivity is not very high particularly when considering vanillin product. Zhu and coworkers reported recently the use of $\mathrm{ReO}_{\mathrm{x}}$ supported on $\gamma-\mathrm{Al}_{2} \mathrm{O}_{3}$ as an efficient catalyst to produce vanillin from Kraft lignin in molten phenol as solvent (Scheme 4) [40]. While the use of phenol is disputable for green chemistry considerations, it led to high selectivity towards vanillin (95\%, based on analyzed products), and could be recovered by distillation for reuse. How ever, as in other reports, the yield remained low $(\leq 7.5 \%)$. Interestingly, while vanillin yield decreased over time (i.e. $7.3 \%$ at

Table 1

Lignin oxidative depolymerization with various perovskites [33-35].

\begin{tabular}{|c|c|c|c|c|}
\hline Ca talyst & $\begin{array}{l}\text { Lignin } \\
\text { conv. } \\
(\%)\end{array}$ & $\begin{array}{l}p- \\
\text { Hy drox ybenzaldehyde } \\
\text { (\%) } 1 \mathrm{~h} / 3 \mathrm{~h}\end{array}$ & $\begin{array}{l}\text { Vanillin } \\
(\%)(\mathrm{t} \mathrm{h}) / \\
3 \mathrm{~h}\end{array}$ & $\begin{array}{l}\text { Synringaldehyde } \\
(\%)(\mathrm{t} \mathrm{h}) / 3 \mathrm{~h}\end{array}$ \\
\hline no & 42 & $0.9 / 1.5$ & $\begin{array}{l}3.2(1) / \\
2.9\end{array}$ & $5.5(1 \mathrm{~h}) / 4.0$ \\
\hline $\mathrm{LaMnO}_{3}$ & 57 & $1.3 / 2.0$ & $\begin{array}{l}4.3(0.5) / \\
3.9\end{array}$ & $9.3(0.5 \mathrm{~h}) / 4.2$ \\
\hline $\mathrm{LaCoO}_{3}$ & 57 & $1.5 / 2.2$ & $\begin{array}{l}4.5(0.5) / \\
4.2\end{array}$ & $\begin{array}{l}10.0(0.8 \mathrm{~h}) / \\
4.8\end{array}$ \\
\hline $\mathrm{LaFe}_{0.9} \mathrm{Cu}_{0.1} \mathrm{O}_{3}$ & 60 & $1.4 / 2.2$ & $\begin{array}{l}4.4(0.7) / \\
3.7\end{array}$ & $\begin{array}{l}10.8(0.5 \mathrm{~h}) / \\
4.9\end{array}$ \\
\hline $\mathrm{LaFe}_{0.8} \mathrm{Cu}_{0.2} \mathrm{O}_{3}$ & 65 & $1.6 / 2.5$ & $\begin{array}{l}4.6(0.7) / \\
4.3\end{array}$ & $\begin{array}{l}11.5(0.5 \text { h) / } \\
4.9\end{array}$ \\
\hline
\end{tabular}

Reaction conditions: aqueous solution of lignin $\left(60\right.$ g.L $\left.\mathrm{L}^{-1}\right), \mathrm{NaOH}\left(2 \mathrm{~mol} . \mathrm{L}^{-1}\right)$, catalyst $\left(3\right.$ g.L $\left.\mathrm{L}^{-1}\right), \mathrm{P}_{\mathrm{O} 2 \text { part. }}: 5$ bar in nitrogen, $\mathrm{P}_{\mathrm{Tot}}: 20$ bar, $120{ }^{\circ} \mathrm{C}$.
$60 \mathrm{~min}, 6.9 \%$ at $80 \mathrm{~min}$ ), it seems that the use of phenol can prevent over oxidation compared to other media. This was accompanied by the formation of other unidentified products issued from lignin.

Concerning the catalyst, the oxidation state of Re was not definitively determined but $\mathrm{ReO}_{3}$ and $\mathrm{Re}_{2} \mathrm{O}_{7}$ species have been identified from XPS and Raman spectroscopy. Efficient recyclability was demonstrated at least 3 times after catalyst recovery by simple filtration. Note that under the same conditions other supported metal oxide $\mathrm{Fe}_{2} \mathrm{O}_{3} / \gamma-\mathrm{Al}_{2} \mathrm{O}_{3}$ gave poor activity. Also, comparison with $\mathrm{ReO}_{\mathrm{x}}$ supported on $\mathrm{CeO}_{2}$ indicates that the slightly higher acidic character of $\gamma-\mathrm{Al}_{2} \mathrm{O}_{3}$ may play a positive role in forming vanillin.

Mixed metal oxide catalysts represent an interesting approach in the oxidative depolymerization of lignin, as it can be with perovskites. For example, Ba rakat and coworkers described recently the use of various $\mathrm{CoFeO}$ mixed metal oxides [41,42]. Alginate was used as a sacrificial template to provide nano-nucleation delivering after calcination mixed metal oxides with relatively well-defined particle size of about $30-50 \mathrm{~nm}$. Several catalysts with varied $\mathrm{Co}: \mathrm{Fe}$ ratios were prepared giving compositions $\mathrm{Co}_{(3-\mathrm{x} x} \mathrm{Fe}_{\mathrm{x}} \mathrm{O}_{4}$ or $\mathrm{Co}_{\mathrm{x}} \mathrm{Fe}_{(2-\mathrm{x})} \mathrm{O}_{3}$. After studies on lignin model polymer prepared by peroxidase-polymerization of G- and/or Smonomer units, the authors addressed the reactivity of an Organosolv lignin extracted from wheat straw. Among the catalysts, $\mathrm{Co}_{1.8} \mathrm{Fe}_{1.2} \mathrm{O}_{4^{-}}$ $\mathrm{Co}_{0.8} \mathrm{Fe}_{1.2} \mathrm{O}_{3}$, that corresponding to Fe:Co 1:1 ratio, demonstrated the best performance showing a positive effect between the two oxides. It formed mixture of aromatic molecules in $10-20 \%$ in which aldehydes (mainly syringaldehyde) are the main compounds observed, using water or water/methanol mixture as reaction medium (Scheme 5). Alkyl aromatics were also observed attributed to demethoxylation of lignin upon catalyst action. When methanol was used as co-solvent it was suggested that alkylation of lignin by methanol occurred as well since their ratio increased. Authors noticed that the yield of aromatics depended on the temperature, but also on the amount of catalyst, and increasing catalyst loading favored aromatic formation. As an explanation, the authors suggested that the basic nature of the catalyst could help to overcome recondensation reactions that often occur during oxidative lignin depolymerization. Thus at $200{ }^{\circ} \mathrm{C}$ and after $4 \mathrm{~h}$ in pure wa ter under diluted oxygen ( $10 \%$ in $\mathrm{N}_{2}, 10$ bar) atmosphere lignin conversion reached ca. $40 \%$ giving syringaldehyde with a selectivity to main $50 \%$ based on identified compounds. The catalyst was recovered, dried then calcined before reuse, and selectivity into main products remained constant over at least 2 more cycles.

\subsection{Metal catalysts}

Metal catalyst are relatively often used in the field of lignin depolymerization, mainly under reductive or inert atmosphere. However, a few reports concern oxidative depolymerization. Cobalt nanoparticles embedded in $\mathrm{N}$-doped porous carbon were reported by Sun et al. as efficient catalysts [43]. The $5 \% \mathrm{Co} / \mathrm{CN}$ catalysts were synthesized by carbonization of Co-ZIF-based metal-organic-frameworks leading to solids presenting a porous structure with interesting $\mathrm{O}_{2}$ adsorption abilities, while the Lewis acid character of the $\mathrm{N}$ sites may enhance lignin interaction with the catalyst. While most of the work concerns molecular model of lignin, the authors reported results related to an Organo-

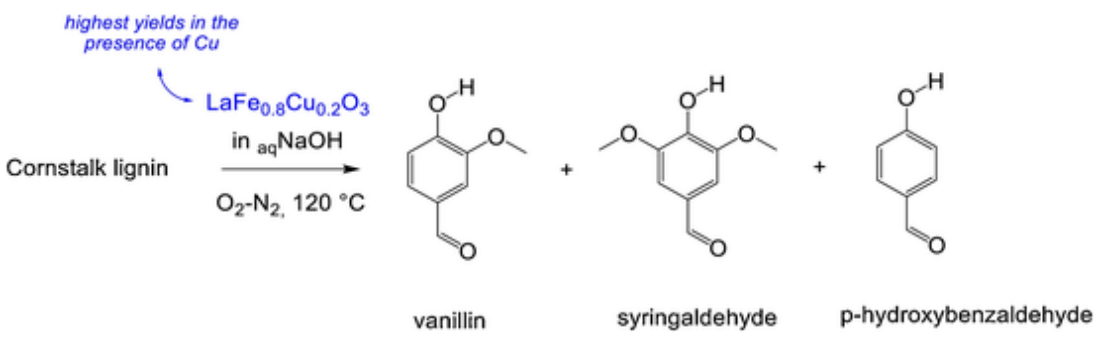

Scheme 3. Lignin oxidative depolymerization with Fe-containing perovskite. 


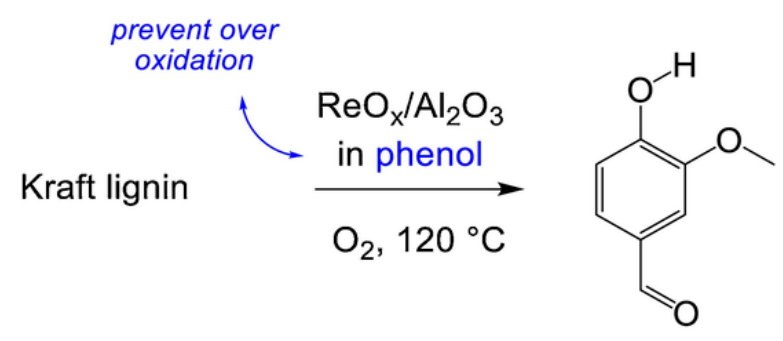

vanillin

Scheme 4. Lignin oxidative depolymerization with supported Re oxide.

solv lignin extracted from birch. Treating this lignin in methanol at $110{ }^{\circ} \mathrm{C}$ under oxygen led to the disappearance of correlation signals corresponding to key structural $\beta$-O-4 bonds in 2D HSQC spectra of recovered lignin. These observations were correlated to the formation of aromatic compounds in the liquid phase in $15 \%$ wt as observed using GC-MS (few compounds were identified, including phenol, syringyl derivatives; no aldehydes, no carboxylic acids, alkylated compounds were reported attesting for alkylation reaction via methanol [30]. Experiments conducted in the presence of TEMPO indicated that the mechanism may involve radical formation. Catalyst recovery was possible using an external magnet. After ethanol wa shing and drying it was reused for lignin model oxidation showing a constant decrease, probably due to $\mathrm{Co}^{\circ}$ oxidation during the first run. The efficiency could be fully restored af ter a reduction step. Gold nanoparticles with $2.1 \mathrm{~nm}$ average size supported on Li-Al layered double hydroxide (LDH) were recently used under $\mathrm{O}_{2}$ atmosphere [44]. After addressing oxidative cleavage of classical lignin bonds in model compounds, the authors engaged the AuNPs/Li-AL LDH catalyst in the oxidative depolymerization of Indulin AT Kraft lignin (from pinewood) and an Organosolv lignin extracted from maple wood using $\gamma$-valerolactone (GVL). DMF was used as solvent in these experiments, and lignin samples were treated in the presence of catalyst at $120{ }^{\circ} \mathrm{C}$ under 1 bar of $\mathrm{O}_{2}$ for $24 \mathrm{~h}$. While Kraft lignin gave low amount of aromatic monomers (ie $<10$ $\%_{\mathrm{w} t}$ ) after reaction and careful extraction, GVL-extracted lignin gave up-to $40 \%$ wt of aromatic monomers, mainly as syringaldehyde. Authors attributed this to the fact that Organosolv process preserves the "native" structure of lignin whereas Kraft process tends to cross-link lignin chains with each other. However, while this is true, from our expertise and literature reports, it is generally also observed that lignin extracted from hardwoods and containing therefore syringyl units are more sensitive towards oxidative depolymerization providing thus higher yields of monomeric units. The basic nature of the catalyst and the size of the Au nanoparticles played a fundamental role, concomitant with a high degree of charge transfer from the support to Au nanoparticles. The authors propose that molecular oxygen was activated at the Au-O-Li interface while the basic sites of the LDH support allow reactant adsorption by deprotonation. Here a two-electron pathway seems to be involved preferentially over a radical mechanism preventing aromatic over oxidation. Recycling experiments performed on a lignin model indicated the absence of metal leaching, however the accumulation of acidic species at the surface prevented full reusability, which could be nevertheless restored after water wa shing.

Among available noble metal based catalysts used in oxidative lignin depolymerization, surprisingly few reports concern Pd-based catalysts, compared to reductive routes. Recently, $\mathrm{Pd} / \mathrm{CeO}_{2}$ was described for oxidative depolymerization of an Organosolv lignin in methanol under oxygen at $185{ }^{\circ} \mathrm{C}$ for $24 \mathrm{~h}$ (Scheme 6) [45]. At reaction completion, vanillin $\left(5.2 \%_{\mathrm{wt}}\right)$, guaiacol $\left(0.9 \%_{\mathrm{wt}}\right)$ and $p$-hydroxybenzaldehyde $\left(2.4 \%_{\mathrm{w}}\right)$ were obtained. The yields are in the range of those given in other reports. However, considering the nature of the products it seems that $\mathrm{Pd} / \mathrm{CeO}_{2}$ catalyst also allowed for demethoxylation, which was not, to our knowledge, reported before under such reaction conditions. Regarding the bond-breaking reaction itself, the authors suggested that $1.5 \%{ }_{\mathrm{wP}} \mathrm{Pd} / \mathrm{CeO}_{2}$ catalyst allows to oxidize $\alpha-\mathrm{OH}$ in the interlink initiating thus $\beta-\mathrm{O} 4-$ bond cleavage by the catalyst to produce phenols and benzaldehydes (see Scheme 6 in Other catalysts section). The $\beta-\mathrm{O} 4-$ bond cleavage can also be realized by $\mathrm{Pd}$-free $\mathrm{CeO}_{2}$ however only after an oxidation step of the $\alpha-\mathrm{OH}$. These results suggest that a synergetic effect between the two components of the catalyst exists, allowing improved yields into aromatics compared to other metal oxide supports. Note that such a mechanism is in agreement with performance of Pd-catalysts in oxidation of benzyl alcohols.

Sales and co-workers have extensively investigated Pd-based catalysts for the oxidative depolymerization of lignin. In a first study, oxidative depolymerization of lignin issued from bagasse was af fected by $2.85 \%{ }_{\mathrm{w}} \mathrm{Pd} / \gamma-\mathrm{Al}_{2} \mathrm{O}_{3}$ showing a clear yield increase for vanillin $\left(0.2 \%_{\mathrm{wt}}\right.$ to $\left.2.5 \%_{\mathrm{wt}}\right)$, syringaldehyde $\left(0.3 \%_{\mathrm{wt}}\right.$ to $\left.3.6 \%_{\mathrm{wt}}\right)$ and $p$ hydroxybenzaldehyde $\left(0.6 \%_{\mathrm{wt}}\right.$ to $\left.4.1 \%_{\mathrm{wt}}\right)$. A kinetic model resulting from these studies indicated that the catalyst did not play a role in

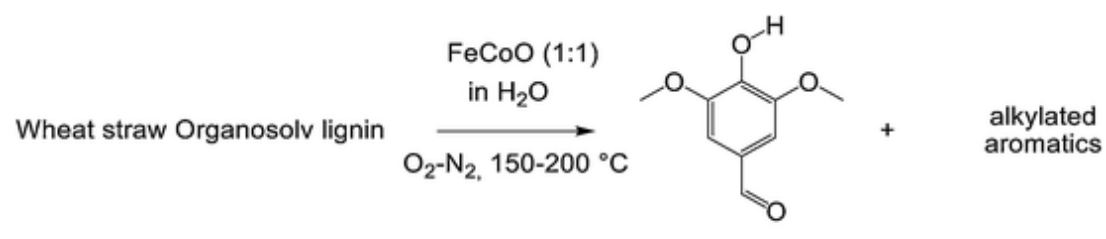

syringaldehyde

Scheme 5. Lignin oxidative depolymerization with Fe and Co mixed oxides.

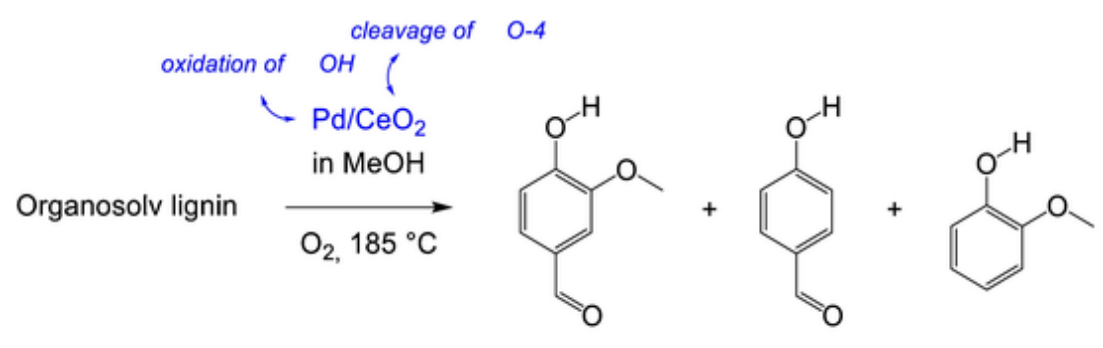

vanillin $\quad$-hydroxybenzaldehyde guaiacol

Scheme 6. Lignin oxidative depolymerization with supported Pd catalyst. 
lignin depolymerization but acts in subsequent transformations, leading mainly to degradation products derived from syringaldehyde $[46,47]$. In other studies performed approximatively at the same time, the authors proceed to bagasse lignin depolymerization in a threephase reactor using a continuous flow procedure. Under these conditions, the best yield of aromatic aldehydes (vanillin and syringaldehyde) reached $12 \%_{\mathrm{wt}}$ which was in agreement with values obtained from pseudo-heterogeneous axial dispersion model [48]. From these data, the authors proposed a process for producing aldehydes from bagasse lignin. Comparing data obtained from a batch reactor to those obtained from a continuous flow reactor shows a decrease in yields of vanillin and syringaldehyde under flow conditions that was attributed to higher resistance to the oxygen mass transfer for the continuous flow reactor. However, the global production of aldehydes increased by approximatively 15-20 times in $2 \mathrm{~h}$ when keeping the same other conditions [46]. This report demonstrates clearly the benefit of transferring process developed initially in a batch reactor to continuous flow trickle-bed reactor since aldehyde production from lignin depends both on lignin conversion and their over oxidation under the reaction conditions.

\subsection{Non-conventional approaches}

In this section, we aim at describing alternative approaches toward oxidative lignin depolymerization. One of them was reported by Muddassar et al. who compared lignin depolymerization within two types of black liquor: a "native" black liquor (ie non-treated); and a black liquor treated by acidification with $\mathrm{CO}_{2}$ with the aim of increasing the production of organic acids [49]. Black liquors of two lignins were considered in this work, a Kraft and a soda lignin (the latter being produced from wheat straw). Depolymerization reactions were conducted under oxygen in the presence or not of an iron-based catalyst (in some cases $\mathrm{H}_{2} \mathrm{O}_{2}$ wa s added as co-oxidant). A temperature range from 170 to $230{ }^{\circ} \mathrm{C}$ was evaluated. Considering native black liquor, whatever the lignin, the iron supported on activated carbon $2.23 \%_{\mathrm{w}} \mathrm{Fe} / \mathrm{AC}$ catalyst had no influence on the reactivity. Only the temperature showed moderate influence on the rate of depolymerization. Thus at $210-230{ }^{\circ} \mathrm{C}$, lignin content decreased by $57-64 \%$ and the weight-average molar mass of lignin polymers dropped from 2.7 to $3.3 \mathrm{kDa}$ to $1.5-1.8 \mathrm{kDa}$ after oxidative depolymerization. Engaging black liquor treated with carbon dioxide changed only slightly the situation. Despite a decreased content of lignin in the solution, depolymerization reactions did not reach expected results as the production of organic acids stayed rather limited. Overall the process is interesting for removing lignin from black liquors but the main outcome concerns its precipitation upon acidification with carbon dioxide (that is on the basis of several processes like LignoBoost) [50]. Authors noticed that the oxygen demand when treating acidified black liquor was lowered. This was attributed to removal of hemicellulose and other polysaccharides by the $\mathrm{CO}_{2}$ treatment, but we believe that it is mostly related to removal of some lignin fragment upon $\mathrm{CO}_{2}$ addition that are more sensitive towards oxidative depolymerization. This assumption is correlated by analyses performed on remaining liquors that showed lower polydispersity, higher weightaverage molar masses and lower lignin content.

Other alternative approaches consist in treating first biomass (wood or lignin) at high temperature $\left(\geq 450{ }^{\circ} \mathrm{C}\right)$ to produce bio-oil that was then further treated under catalytic or not conditions. Valle et al. reported the pyrolysis of pine sawdust at $450{ }^{\circ} \mathrm{C}$ followed by treatment in a two-stage reactor consisting of a thermal-treatment unit followed by a catalytic treatment unit [51]. The catalyst was $1 \%{ }_{\mathrm{w}} \mathrm{Ni} / \mathrm{HZSM}-5$. Catalyst deactivation by coke formation occurred but was reduced by co-feeding an optimal amount of methanol, thanks to the water evolved from methanol dehydration on the acid sites of the catalyst, which also increased the selectivity towards aromatics (mainly BTX). Note that this study was performed under neutral He in the gas phase.
Close to that approach Lofti et al. reported procedures to convert lignin to carboxylic acids in gas phase. In a first study, an alkaline solution of Kraft lignin wa sinjected inside a fluidized bed catalytic reactor operating above $330{ }^{\circ} \mathrm{C}$ for $15 \mathrm{~min}$ under an $\mathrm{O}_{2}$ - $\mathrm{Ar}$ atmosphere. Catalysts were based on vanadium, a metal often used for oxidations of hydrocarbons. Vanadium pyrophosphate catalysts $(\mathrm{VO})_{2} \mathrm{P}_{2} \mathrm{O}_{7}-(\mathrm{VO})_{2} \mathrm{P}_{4} \mathrm{O}_{12}$ gave preferentially maleic anhydride together with other carboxylic acids while coke, carbon oxide and hydrogen were also produced. Over $\mathrm{VMoO} / \mathrm{Al}_{2} \mathrm{O}_{3}$ catalysts, lactic acid together with formic, acrylic and maleic acid were obtained [52]. In both cases coke formation was shown to deactivate the catalysts, but efficiency could be partially recovered by an in situ calcination step. Later the same authors revisited the process with the aim of minimizing coke and char formation keeping the activity of the catalysts. They associated in the same reactor a tw o-stag e gas phase catalytic process: treatment of a bed of solid lignin followed by oxidative catalytic treatment of evolved compounds [53]. Several reactor configurations were evaluated, including thermal oxidative steam cracking $\left(\mathrm{T} \leq 550^{\circ} \mathrm{C}\right)$ prior to oxidation which produced lower coke and char on the catalyst surface, fa voring aromatics formation. Over $\mathrm{VMoO} / \mathrm{Al}_{2} \mathrm{O}_{3}$ or $\mathrm{VMoO} / \mathrm{HZSM}-5,23-25 \%$ bio-oil was obtained consisting mainly in maleic acid ( $20 \%$ of selectivity). Replacing both supports by $\mathrm{TiO}_{2}$ increased maleic acid selectivity to $45 \%$. Over VWO/HZSM-5, selectivity turned to the formation of butyric acid.

\subsection{Other catalysts}

Another kind of catalytic system, based on metal salts has been reported, which can be regarded differently than homogeneous metal complexes and related systems. Very few studies deal with the use of real lignin, staying generally in case studies of lignin models. Moreover when lignin was considered, often $\mathrm{H}_{2} \mathrm{O}_{2}$ was used as oxidant, and, therefore these reports do not fall within the scope of this article. Nevertheless some examples with $\mathrm{O}_{2}$ as oxidant in the presence of metal salts of mainly copper and cobalt have been reported for oxidative lignin depolymerization. Villar et al. used $\mathrm{CuSO}_{4}$ and $\mathrm{CoCl}_{2}$ salts given as not soluble in the basic liquid reaction phase containing eucalyptus Kraft lignin. They noticed that they did not significantly improve lignin conversion (compared to the non-catalyzed reaction) into aromatic compounds and syringaldehyde was the main product at temperatures of $170-190{ }^{\circ} \mathrm{C}$. This was due to over-oxidation delivering low molecular weight molecules (mainly organic acids) [39]. To improve the solubility of the catalysts, a $\mathrm{Co}$ (Salen) complex and a $\mathrm{CuSO}_{4}$-ethylene glycol system were used but none of them gave better results, indicating that the catalyst phase did not play an important role in oxidative depolymerization with such metals. However, no data were provided to show that the $\mathrm{Co}$ (Salen) complex was effectively fully soluble under the reaction conditions. Recently, Zhou et al. reported the use of Co (Salen) complex grafted on graphene oxide (GO) for oxidative depolymerization of lignin [54]. An eucalyptus Organosolv lignin solubilized in MeCN-THF 10:1 mixture was treated at $80{ }^{\circ} \mathrm{C}$ under air. Co(Salen)/ GO showed the highest activity compared to homogeneous complex or other supports like MCM-48, NaY or SSZ-13. Vanillin was mainly produced which is rather surprising, since eucalyptus wood contains mostly syringyl units. The support seemed to play an important role here; however no data was given on the intrinsic potential activity of the support itself. Recyclability experiments were performed af ter catalyst filtration and all systems showed a decrease in vanillin formation over 10 cycles. Nevertheless, the Co(Salen)/GO system appeared to be slightly the most stable, probably due to better anchoring of the metal sites.

Zhao et al. reported a procedure consisting of pre-oxidizing lignin before metal catalyzed bond cleavage [55]. In a first step, an Organosolv lignin was pre-oxidized using a mixture of $\mathrm{DDQ} / \mathrm{tBuONO} / \mathrm{O}_{2}$ that selectively oxidized to ketone the benzylic $\mathrm{OH}$ group on the $\beta-\mathrm{O}-4$ moiety. The catalysts allowed then the cleavage of oxidized $\beta-O-4$ bonds at 
$180{ }^{\circ} \mathrm{C}$ in methanol under $\mathrm{O}_{2}$. The authors used triazine frameworks as heterogeneous catalytic systems (Scheme 7). Triazine frameworks were prepared by polymerization of various dicyanobenzenes in the presence of catalytic $\mathrm{ZnCl}_{2}$ supposed to be removed during the synthesis. The catalyst was therefore presented as metal free although no proof of the absence of residual $\mathrm{Zn}$ was given to establish the full organocatalysis nature of the system. Reusability of the catalyst was demonstrated on a lignin model showing over 7 runs slight conversion decrease and similar selectivity. The deactivation would be due to product adsorption or partial catalyst oxidation. This methodology was based on that described previously by Lancefield et al. who used a $\mathrm{Zn} / \mathrm{NH}_{4} \mathrm{Cl}$ catalytic system leading to $\mathrm{C}_{9}$-syringyl-based units in $5 \%$ yield [56]. Zhao et al. reported only proof of oxidation of original lignin that can be due to the use of $\mathrm{DDQ} / \mathrm{tBuONO} / \mathrm{O}_{2}$ mixture. The main interest from this procedure is the capacity to depolymerize lignin to its constituting "original" monomeric $\mathrm{C}_{9}$-units.

\section{Catalytic reductive depolymerization of lignin}

The catalytic reductive depolymerization of lignin is an important and challenging topic, inspired by well-known early works [57-61]. As for the catalytic oxidative depolymerization section, only the catalytic depolymerization of technical lignins with heterogeneous catalysts will be reported. Even if they can afford very precious and fundamental insights into the mechanism, the studies dealing with catalytic conversion of model compounds will not be described here. One point to be also clarified is the amount of catalyst employed in respect to the biomass feed. Effectively, sometimes, high ratio of monomers was obtained from lignin with relative huge amount of catalyst. Here, only the works with reasonable catalyst/biomass ratio have been considered in order to stay in a realistic catalytic domain.

Due to the deep transformations occurring in native lignin structure during the fragmentation processes the depolymerization of technical lignins meets the issue of the presence of carbon-carbon bonds between units which makes the cleavage to monomers more difficult. Under reductive conditions, the thermocatalytic cleavage of ether bonds, like $\beta-\mathrm{O} 4-$ linkage, is quite easy under the operating conditions used $\left(250-400{ }^{\circ} \mathrm{C}, 30-200 \mathrm{bar}\right)$ and leads to phenolic units that can be further deoxygenated in the presence of an adequate catalyst to benzene derivatives. The reactions observed during the lignin depolymerization under reductive conditions are summarized in Table 2 . The type of solvent used during the process may have a strong impact on the reactivity and is a real issue. Most of the time, protic or hydrogen-donor solvents are used, but, under operating conditions, the solvent is usually not inert and can react directly with lignin fragments. This fact severely complicates product separations and further analysis.

\subsection{Solvent free hydroconversion}

Several groups have proposed to perform the catalytic liquefaction towards aromatics and phenolics in the absence of solvent in order to simplify work-up and characterization procedures after reaction. For the cases of employing solvent free conditions, molten lignin (melting point of lignin is reported to be $200-300{ }^{\circ} \mathrm{C}$ depending on the type of lignin) can act as the initial solvent, later diluted with low mass molecular lignin products formed by cleavage. Following earlier studies, recent advances are presented in Table 3 [62-66].

The main disadvantage of this process is the very high pressure of $\mathrm{H}_{2}$ needed. According to pioneering study [60], the yield of liquid phase increased from $18 \%_{\mathrm{wt}}$ to $63 \%_{\mathrm{wt}}$ by increasing initial pressure from 20 to 120 bar. Similar results were observed by Horáček et al. [67] using a NiMo sulfide catalyst. Hence, high $\mathrm{H}_{2}$ pressure seems to be necessary to obtain a high yield of liquid in the absence of solvent. This can be explained by the fact that under high $\mathrm{H}_{2}$ pressure, hydrogen can diffuse better into the mixture and available hydrogen atoms can quickly stabilize unstable free radicals and avoid recondensation reactions. Thereby the liquid yield increases and the solid yield decreases with increasing pressure. In addition, the better $\mathrm{H}_{2}$ diffusion to the catalyst may favor hydrogenolysis steps.

The catalysts employed under these conditions were mostly supported noble metals $[62,64]$, metal sulfide $[63,65]$ and metal phosphide [66]. The liquid yield can reach $80 \%$ wt especially with noble metal catalysts ( $\left.\mathrm{Pd} / \mathrm{C}, \mathrm{Ru} / \mathrm{TiO}_{2}, \mathrm{Ru} / \mathrm{C}\right)$ and aromatic monomer yield vary from 10 to $30 \%{ }_{\mathrm{wt}}$ of the starting lignin depending on the catalyst. The nature of the initial lignin may of course impact drastically the monomer yield and also the solid residues. For instance, a pyrolytic lignin has a much lower molecular weight compared to Kraft lignin. It was demonstrated that using the same catalyst the yield of aromatic monomers was higher from pyrolytic lignin compared to Alcell and the highest yield into monomers with pyrolytic lignin from forestry residue (including alkanes, ketones) was $51 \%_{\mathrm{wt}}$ [64]. From Kraft lignin, the best yield obtained into monomers is $45.7 \%_{\mathrm{wt}}$ (including alkanes in addition to phenolics and BTX) with activated carbon supported NiMo phosphide catalysts [66]. Those catalysts have a higher activity compared to metal sulfide catalysts with no need of additional sulphur in the feed to preserve sulfidation state for sulfide catalysts. Since Kraft lignin contains sulphur, noble metals would be poisoned and were not tested. The amount of solid residues reaching $35 \%$ from Kraft lignin with the most acidic supports can be lowered by the use of a basic support [63]. The yield of solid residue was negligible in case of noble metals catalysts with pyrolytic or Alcell lignin.

To conclude, solvent free conditions facilitate the product work-up and mass balance closure and allow the formation of large amount of organic liquid containing aromatic monomers. However, an obvious draw back is that the yield of non-convertible char formation seems to be more severe than under solvent-assisted conditions with similar cat-

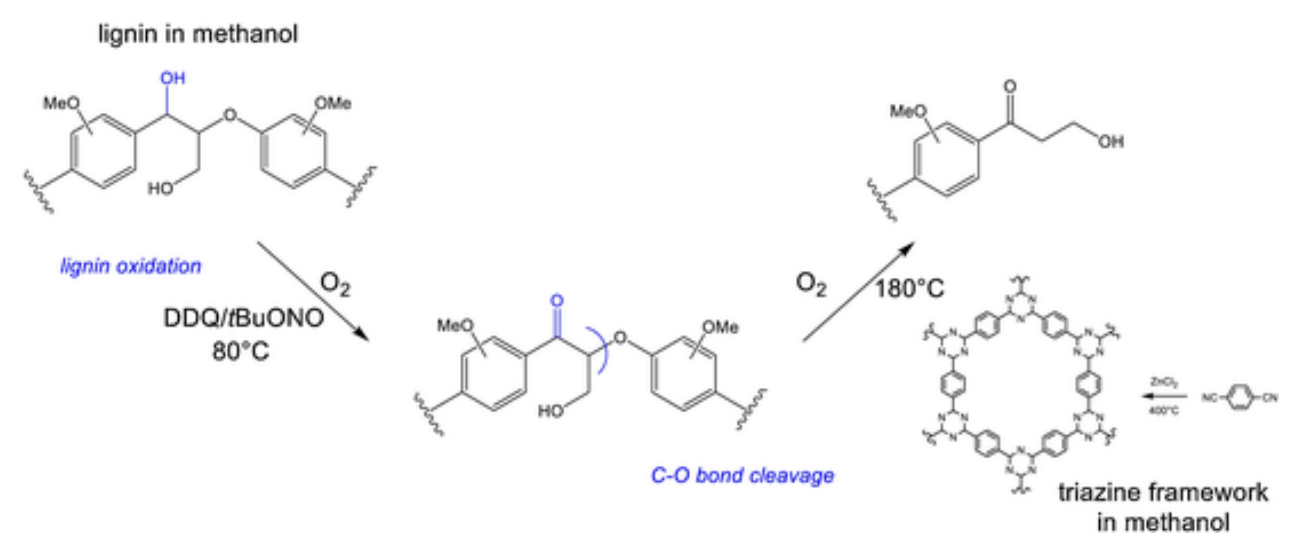

Scheme 7. Lignin oxidative depolymerization with triazine frameworks. 
Table 2

Reactions occurring for lignin depolymerization un der reductive conditions.

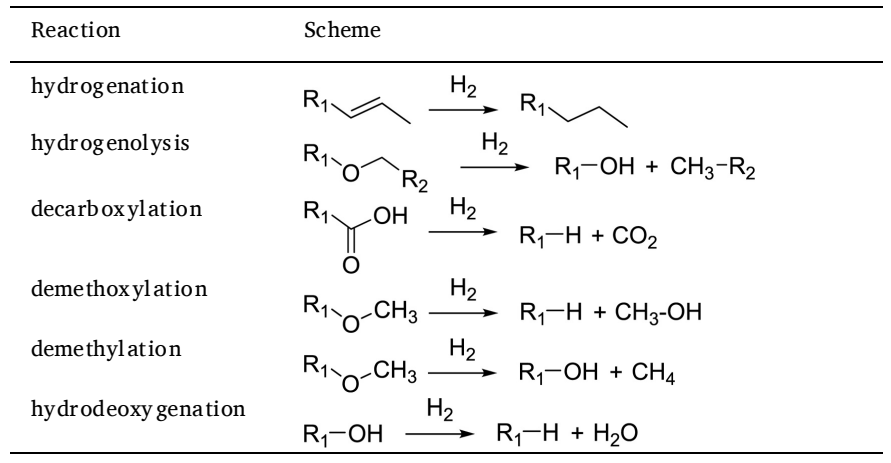

alysts and lignin (see also Fig. 2) [68]. In order to av oid this disadvantage for achieving a high yield of liquid products, reaction pressure must be sufficiently high ( $>200$ bar at operating temperature). Moreover, high reaction temperature is required to favor the depolymerization of lignin. Variation of original lignin and extraction methods make it difficult to draw general conclusions regarding the best type of catalyst and operating conditions. Overall, under solvent free conditions the operating conditions are really harsh. Concerning the aromatic monomeric product yield, alkylphenolic and BTX yields can reach respectively $25 \%_{\mathrm{wt}}$ and $15 \%_{\mathrm{we}}$

\subsection{Hydroconversion in inert solvents}

Inert solvents with poor hydrogen donating ability, and no interaction with lignin derivatives have also been used. Some significant examples have been reported using dodecane, naphthalene and 1methylnaphthalene $[59,68,69]$. Dodecane and 1-methylnaphthalene were chosen as external solvents due to their supposed stability at high temperature and high pressure. How ever, the lignin hydroconversion in these solvents leads to low liquid formation and low monomer yields. For instance, using dodecane instead of tetralin for the depolymerization of a wheat straw soda lignin with NiMoS catalyst decreased the yield of liquid from $60 \%_{\mathrm{wt}}$ to $30 \% \mathrm{wt}_{\mathrm{wt}}$ (Fig. 2). Moreover, it was observed that 1-methylnaphthalene was quite reactive to lignin fragments since $6 \%{ }_{\mathrm{wt}}$ of naphthalene and $8 \%_{\mathrm{wt}}$ of dimethylnaphthalene were found in the products. On the contrary, dodecane was found an efficient solvent for the catalytic depolymerization of a cellulolytic lignin over silicaalumina supported $\mathrm{Ni}$ catalyst affording cycloalkanes under $\mathrm{H}_{2}$ pressure [70]. Overall, the addition of inert solvents like dodecane, and 1methylnaphthalene may favor catalytic performance by improving gas-liquid-solid contacts compared to solvent-free conditions. Consequently, the catalyst/lignin mass ratio employed was mostly lower than under solvent-free conditions. Nevertheless, the performance obtained using those solvents was poor and in all cases using inert solvents, the yields of phenolics and aromatic products were relatively low, showing no distinct improvement compared to solvent-free condi-

Table 3

Solvent free hydroconversion of lignin in batch reactor.

\begin{tabular}{|c|c|c|c|c|c|c|c|c|}
\hline Lignin & Ca talyst & Ca talyst/Lignin $\left(\%_{\mathrm{wt}}\right)$ & $\mathrm{T}\left({ }^{\circ} \mathrm{C}\right)$ & $\mathrm{T}(\mathrm{min})$ & $\mathrm{P}$ (bar) & Max. aromatic monomers yield $\left(\%_{\mathrm{wt}}\right)$ & Liquid yield $\left(\%_{w t}\right)$ & Ref \\
\hline \multirow[t]{10}{*}{$\mathrm{AL}$} & $\mathrm{Ru} / \mathrm{C}$ & 5 & 400 & 240 & $100 *$ & PHE (9.0) & 63.9 & [62] \\
\hline & & & & & & BTX (3.2) & & \\
\hline & $\mathrm{Ru} / \mathrm{TiO}_{2}$ & & & & & PHE (9.1) & 78.3 & \\
\hline & & & & & & BTX (2.5) & & \\
\hline & $\mathrm{Pd} / \mathrm{C}$ & & & & & PHE (8.1) & 67.5 & \\
\hline & & & & & & BTX (4.3) & & \\
\hline & $\mathrm{Pd} / \mathrm{Al}_{2} \mathrm{O}_{3}$ & & & & & PHE (7.3) & 75.1 & \\
\hline & & & & & & BTX (2.0) & & \\
\hline & $\mathrm{Cu} / \mathrm{ZrO}_{2}$ & & & & $125^{*}$ & PHE (4.7) & 71.8 & \\
\hline & & & & & & BTX (1.3) & & \\
\hline \multirow[t]{8}{*}{ KL } & NiMoS/AC or $\mathrm{MgO}-\mathrm{La}_{2} \mathrm{O}_{3}+$ DMDS & 5 & 350 & 240 & $100 *$ & PHE (16) & $50-57.8$ & [63] \\
\hline & & & & & & BTX (5.9) & & \\
\hline & $\mathrm{NiMoS} / \mathrm{Al}_{2} \mathrm{O}_{3}$ or $\mathrm{ZSM}-5+$ DMDS & & & & & PHE (10.5) & $40.8-43.2$ & \\
\hline & & & & & & BTX (3) & & \\
\hline & $\mathrm{CoMoS} / \mathrm{AC}$ or $\mathrm{MgO}-\mathrm{La}_{2} \mathrm{O}_{3}+$ DMDS & & & & & PHE (12.5) & $49.5-52.6$ & \\
\hline & & & & & & BTX (5.3) & & \\
\hline & $\mathrm{CoMoS} / \mathrm{Al}_{2} \mathrm{O}_{3}$ or ZSM-5 + DMDS & & & & & PHE (12) & $29.8-48$ & \\
\hline & & & & & & BTX (5.3) & & \\
\hline \multirow[t]{2}{*}{ PL } & $\mathrm{Ru} / \mathrm{C}$ & 5 & 400 & 240 & $100^{*}$ & PHE (20.5) & $75.4-75.8$ & [64] \\
\hline & & & & & & BTX (14.1) & & \\
\hline \multirow[t]{6}{*}{ KL } & Limonite $\left(\mathrm{Fe}_{2} \mathrm{O}_{3}+\mathrm{FeOOH}\right)+$ DMDS & 5 & 350 & 240 & $100 *$ & PHE (11.7) & 49 & [65] \\
\hline & & & & & & BTX (1.8) & & \\
\hline & & & 400 & & & PHE (12.1) & 36 & \\
\hline & & & & & & BTX (1.8) & & \\
\hline & & & 450 & & & PHE (16.7) & 33 & \\
\hline & & & & & & BTX (4.1) & & \\
\hline \multirow[t]{10}{*}{ KL } & $\mathrm{Ni} 2 \mathrm{P} / \mathrm{AC}$ & 5 & 400 & 240 & $100^{*}$ & PHE (9) & 39.2 & [66] \\
\hline & & & & & & BTX (3.1) & & \\
\hline & $\mathrm{MoP} / \mathrm{AC}$ & & & & & PHE (22.4) & 61.2 & \\
\hline & & & & & & BTX (8) & & \\
\hline & NiMoP/AC & & & & & PHE (22.5) & 64.3 & \\
\hline & & & & & & BTX (7.6) & & \\
\hline & NiWP/AC & & & & & PHE (17.9) & 59.3 & \\
\hline & & & & & & BTX (5.3) & & \\
\hline & NiMoP/AC & 10 & 400 & 120 & 100 & PHE (25) & 70.6 & \\
\hline & & & & & & BTX (8.7) & & \\
\hline
\end{tabular}

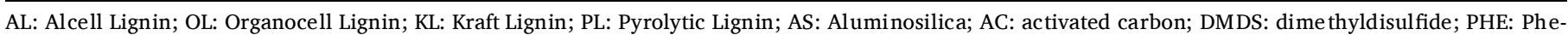
nols; BTX: Benzene, Toluene, Xylene.

* Initial pressure at room temperature. 


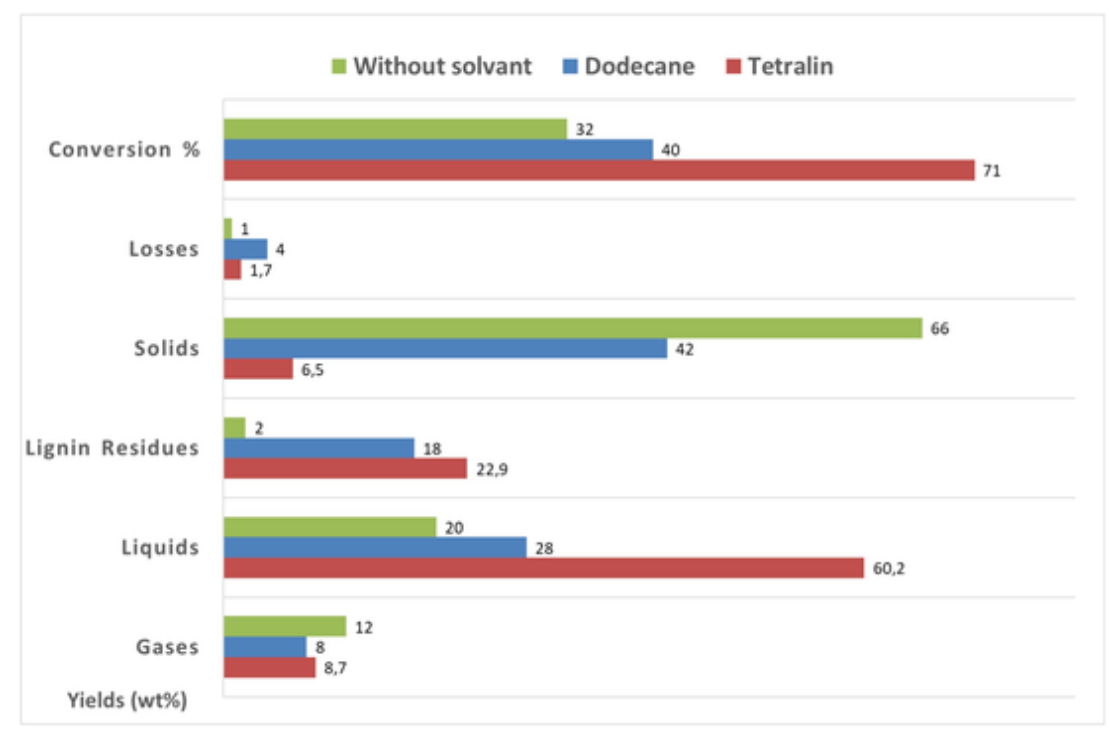

Fig. 2. Lignin catalytic hydroconversion with $\mathrm{NiMoS} / \mathrm{Al}_{2} \mathrm{O}_{3}$ in tetralin, dodecane or without solvent $\left(350{ }^{\circ} \mathrm{C}, 80\right.$ bar) (adapted from [86]).

tions, and complicating product recovery. Thus an inert solvent provides little advantage for lignin hydroconversion.

\subsection{Hydroconversion in hydrogen-donor solvents}

An attractive alternative inspired by early coal liquefaction studies is the use of hydrogen donating solvents [71]. These solvents produce $\mathrm{H}$ radicals under the reaction conditions and in the presence of a catalyst. The use of hydrogen-donor solvents allows lignin depolymerization to proceed without additional $\mathrm{H}_{2}$ and at milder conditions. In this case the process is similar to a liquid reforming or transfer hydrogenation process. Nevertheless the addition of gaseous $\mathrm{H}_{2}$ may improve the hydrodeoxygenation (hydrogenolysis) reactions that could provide deoxygenated aromatics. In this case the process is named hydroconversion or hydroprocessing. In the following sections will be reported the main recent work with hydrogen-donor solvents, which have been arbitrary classified in two categories (protic and aprotic).

\subsubsection{Protic hydrogen-donor solvents}

Typical examples of protic hydrogen-donor solvents used in lignin depolymerization include water, alcohols and formic acid [72-77]. In general, these protic solvents are used at a temperature and pressure allowing a subcritical or supercritical state where the fluid has a strong solva ting power which can have a positive impact on the lignin depolymerization (Table 4). Under hydrothermal conditions, the degradation of lignin under $\mathrm{H}_{2}$ leads to catechols with high yields and Strüven et al. showed that the use of Raney Ni catalysts under $\mathrm{H}_{2}$ pressure was efficient to obta in phenols [72]. When Barta et al. depolymerized a lignin extracted by methanol from nutshells of candlenut, using $\mathrm{Cu}$ porous metal oxide in methanol, they showed that the lignin could be selectively cleaved into $\mathrm{C}_{9}$-catechols with a yield of $54.8 \%_{\mathrm{wt}}$ [78]. It was further demonstrated that the $\mathrm{Cu}$ catalyses decomposition of methanol to produce $\mathrm{CO}$ and $\mathrm{H}_{2}$. In this way, methanol serves as the in situ hydrogen source for the hydrogenolysis-hydrog enation reactions. However in this work, a high catalyst-to-lignin ratio wa s needed and the lignin was obtained through a lignin-first extraction process. Oregui-Bengoechea et al. studied the effect of various hydrogen-donor alcohols solvents in mixture or not with formic acid to assess the role of each [76]. They suggested that formic acid not only acted as hydrogen-donor (by degradation to $\mathrm{CO}_{2}$ and $\mathrm{H}_{2}$ ) but also reacted with lignin fragments through formylation reactions and helped the depolymerization. The presence of alcohols allowed for stabilization of the formed monomers and ethanol was the most efficient. Other studies [79,80] compared ethanol and longer alcohols. Ethanol was shown to be a better solvent than water or other alcohols because it can act as a capping agent, and stabilize the phenolic intermediates by O-alkylation of hydroxyl groups and by C-alkylation of the aromatic rings resulting in a high yield of liquid. However, isopropanol was found to have good properties for hydrogen transfer suppressing better the formation of solid residue. This solvent was successfully used in catalytic cracking of Kraft Lignin

Table 4

Hydroconversion of lignin in the presence of protic hydrogen-donor solvents.

\begin{tabular}{|c|c|c|c|c|c|c|c|c|c|}
\hline Lignin & Solvent & Ca talyst & Ca taly st/Lig nin $\left(\%_{\text {wt }}\right)$ & $\mathrm{T}\left({ }^{\circ} \mathrm{C}\right)$ & $\mathrm{t}(\mathrm{h})$ & $\mathrm{P}\left(\mathrm{H}_{2}\right)$ (bar) & Ma in products $\left(\%_{\mathrm{wt}}\right)$ & Liquefaction $\left(\%_{w t}\right)$ & Ref \\
\hline OL & water & Raney Ni & 12 & 360 & 3 & $70^{*}$ & phenols + catechol (10.1) & n.d. & [72] \\
\hline OL & ethanol-water & $\mathrm{Ru} / \mathrm{C}, \mathrm{Pd} / \mathrm{C}, \mathrm{Pt} / \mathrm{C}$ & 20 & $200-275$ & $1.5-3$ & $10-60 *$ & $\begin{array}{l}\text { 4-ethylphenol } \\
\text { 4-ethyl-guai acol }\end{array}$ & n.d. & [73] \\
\hline AL & ethanol & $\mathrm{ZnCl}_{2}$ & 50 & 300 & 2 & $70 *$ & $\begin{array}{l}\text { phenols (15.79) } \\
\text { guaiacolics (15.09) }\end{array}$ & 75.8 & [74] \\
\hline SL & ethanol & $\mathrm{CuMgAlOx}$ & 50 & 300 & $1-20$ & $10 *\left(\mathrm{~N}_{2}\right.$ or $\left.\mathrm{H}_{2}\right)$ & $\begin{array}{l}\text { phenols (12) } \\
\text { BTX (8) }\end{array}$ & n.d & [75] \\
\hline EL & form ic acid-al cohols & $\mathrm{NiMo} /$ sulfated $\mathrm{Al}_{2} \mathrm{O}_{3}$ & 10 & 320 & 6 & $17.5^{*}$ & n.d. & 26.6 & [76] \\
\hline OL & ethanol- water & $\begin{array}{l}\mathrm{Ru} / \mathrm{C} \\
\mathrm{Ru} / \mathrm{NC} \\
\mathrm{Ru} / \mathrm{CM} \\
\mathrm{Ru} / \mathrm{NCM}\end{array}$ & 20 & 300 & 2 & 10 & alkylphenols (30) & n.d. & [77] \\
\hline
\end{tabular}

OL: Organosolv Lignin; ML: Methanol-extracted Lignin; PL: Pyrolytic Lignin; AL: Alkali Lignin; SL: Soda Lignin; EL: Eucalyptus Lignin; PMO: Porous Metal Oxide; NC, CM, NCM: N-doped carbon.

* Initial pressure at room temp erature. 
on various zeolite-supported $\mathrm{NiCu}$, and in this case alkanes and cycloalkanes were mainly obtained [81]. The advantage of these solvents is that hydrogen transfer is very efficient in the presence of a wellchosen catalyst and there is no need of $\mathrm{H}_{2}$ pressure to depolymerize lignins and to get monomers. How ever, in most of the cases with these solvents, the hydrogenolysis led mainly to phenolic and guaiacylic monomers and deoxygenated aromatics (BTX) were scarcely formed. For instance the use of isopropanol in the presence of $\mathrm{PtRe} / \mathrm{TiO}_{2}$ with various home-extracted lignins under mild conditions led to obtain methoxyphenolics in quite high yield $\left(18.7 \%_{\mathrm{wt}}\right)$. However, depending on the type of lignin, the performance can be less interesting [82]. For instance application to a conventional black liquor lignin showed much lower yields of phenolics because of the lack of $\beta-\mathrm{O} 4-$ inter-unit bonds. Similarly, Ru/N-Doped carbon catalysts were developed for the conversion of an Organosolv lignin to phenolic monomers, mostly alkylguaiacyl and alkylsyringyls [77].

To conclude, the protic hydrogen-donor solvents are used to stabilize the highly reactive lignin fragments. However, their participation in the reaction is unavoidable. Furthermore, the effect of protic solvents can also be at tributed to an improved solubility of lignin and reaction products.

\subsubsection{Non-protic hydrogen-donor solvents}

Tetralin is the most employed non-oxygenated solvent as a hydrogen-donor solvent in lignin liquefaction [71] (Table 5). The reason is that it can be dehydrogenated to naphthalene under hydroconversion conditions $\left(>250{ }^{\circ} \mathrm{C}\right.$ ) and the free $\mathrm{H}$ radicals formed are directly injected in the liquid phase to neutralize alkyl or alkoxy radicals and improve the $\mathrm{H}_{2}$ mass transfer into the liquid phase (Scheme 8).

To ensure a reversible process, a catalyst is required for the reverse hydrogenation of naphthalene to tetralin. Early studies focused on the use of tetralin as a sole hydrogen-donor to replace pressurized $\mathrm{H}_{2}$ for lignin hydrotreatment, so-called solvolysis [83,84]. However, in this case the yield of liquid formed was very low, due to relatively low temperature and the absence of catalyst to help the cleavage of bonds betw een phenolic units. As said above, the importance of hydrogen donor effect can be illustrated by comparing results with tetralin and naphthalene and, the liquid yield with tetralin wa s almost four times higher than that with naphthalene, with much less char. It appears therefore that in the absence of a hydrogen-donor solvent, the intermediate free radicals recombine quickly to produce char. Consequently, using a hydrogen-donating solvent as the sole hydrogen source, the hydrogen content is evidently not sufficient to react with all rapidly formed free radicals. To obtain more valuable liquid products, either supplying additional hydrogen or slowing down lignin depolymerization should be taken into consideration. Following those investigations, Klopries et al. performed the conversion of rye straw lignin with sulfided red mud and sulfided CoMo with tetralin under $\mathrm{H}_{2}$ pressure [85]. The distribution of products using two different catalysts showed that $95 \%_{\mathrm{wt}}$ of lignin was converted into gas and liquid products. CoMoS catalyst led to higher yields into gasoline-like products (deoxygenated hydrocarbons) while red mud led preferentially to phenolics and heavy oil. However, it is impossible to get further catalytic effects since detailed liquid distribution was not mentioned in this work. Thring et al. also underlined the need for added hydrogen to achieve higher liquid yield and lower char formation [86]. It was also pointed out that the high yield of either solid char or residual lignin was governed by reaction temperature. At high severity, significant cracking of lignin occurred and the high yield of solid char was due to insufficient amount of hydrogen in the batch reactor. Comparing two hydrogen-donor solvents (isopropanol and tetralin) with a non-hydrogen-donor solvent (naphthalene) for the non-catalytic lignin solvolysis, Kim et al. observed that demethoxylation reaction did not occur in the absence of hydrogen-donor solvent [87]. Secondly, they performed a series of experiments in tetralin with varying reaction time between 0.25 and $1.7 \mathrm{~h}$. NMR analysis of residual lignin suggested the following sequence of reactivity for functional groups in hydrocracking: aliphatic $\mathrm{OH}>$ aromatic $\mathrm{OCH}_{3}>$ aromatic $\mathrm{OH}$. Besides, from the analysis of the liquid fraction, the relatively large quantities of $\mathrm{C}_{1}$-side-chains as well as phenolic products with no sidechains suggests strongly that homolytic cleavage betw een $\alpha$ and $\beta$ carbon atoms as well as betw een the ring and the $\alpha$ carbons are frequent in hydrocracking.

Following these studies, the hydroconversion of lignin was undertaken on classical NiMo sulfide catalysts in tetralin in a batch reactor [68]. The reactor wa s equipped with a $\mathrm{H}_{2}$ reserve to keep the total pressure unchanged and $\mathrm{H}_{2}$ consumption was followed. The identification of the gas, liquid and solid fractions was investigated using a complete products-recovery protocol and comprehensive techniques as $\mu$-GC, GCxGC-MS, GC-FID, GPC and NMR (HSQC). Characterization of the used soda lignin by NMR and GPC included the various lignin residues obtained after conversion to identify the changes occurring on the lignin backbone. In addition, the vaporisable fraction of liquids was analyzed by GCXGC and identification and quantification were completely achieved by successive use of mass and FI detectors (Fig. 3) [88]. From all of this, it appeared that after the depolymerization, the hydrodeoxygenation reactions occurred simultaneously on lignin residues, oligomers and monomers. The limitation of this work wa s the use of a batch system. Effectively, even if the reactor was opened to a $\mathrm{H}_{2}$ reserve to keep the total pressure constant, the formation of gaseous products increased with the residence time, leading to a decrease of $\mathrm{H}_{2}$ partial pressure in the reactor. In addition, it was suggested that wa ter formed during the hydrodeoxygenation of aliphatic alcohols and methoxyphenols could be detrimental to the catalyst action in that system. The batch system was thus upgraded to a dynamic semi-batch setup opened on the gas-phase and equipped with a reflux system and a $\mu$ GC to analyse gas online [89]. This system allowed the recovery of

Table 5

Catalytic hydroconversion in the presence of tetralin as apolar hydrogen-donor solvents.

\begin{tabular}{|c|c|c|c|c|c|c|c|c|c|}
\hline Lignin & Process & Ca talyst & Ca talyst/Lignin $\left(\%_{\mathrm{wt}}\right)$ & $\mathrm{T}\left({ }^{\circ} \mathrm{C}\right)$ & $\mathrm{t}(\mathrm{h})$ & $\mathrm{P} \mathrm{H}_{2}$ (bar) & Ma in products $\left(\%_{\mathrm{wt}}\right)$ & Liquefaction $\left(\%_{\mathrm{wt}}\right)$ & Ref \\
\hline RL & B & $\begin{array}{l}\text { Red mud(S) } \\
\text { CoMo(S) }\end{array}$ & 5 & 400 & 4 & $150^{*}$ & phenols $(18.0-21.3)$ & $75-78$ & [85] \\
\hline SL & B & $\mathrm{NiMoS} / \mathrm{Al}_{2} \mathrm{O}_{3}$ & 10 & 350 & $1-28$ & 80 & phenols + aromatics $(>15)$ & 78 & {$[68,88]$} \\
\hline SL & SB & $\mathrm{CoMoS} / \mathrm{Al}_{2} \mathrm{O}_{3}$ & 10 & 350 & $1-15$ & 80 & phenols + aromatics (17) & $\begin{array}{l}75 \\
\text { organic liquid: } 63\end{array}$ & [89] \\
\hline LS, KL & $\mathrm{B}^{\#}$ & $\begin{array}{l}\mathrm{FeS} / \mathrm{C} \\
\text { FeS/Lignin }\end{array}$ & 10 & $435-500$ & 1 & $100 *-300$ & al kylphenols, al kylbenzenes & $35-60$ & [91] \\
\hline KL & $\mathrm{SB}^{* *}$ & $\left(\mathrm{Fe}_{2} \mathrm{O}_{4}+\mathrm{S}_{2}\right) \mathrm{FeSx}$ & 6 & $380-485$ & 1 & 400 & al kylphenols & $\begin{array}{l}70 \\
\text { or ga nic liquid: } 50.6\end{array}$ & [92] \\
\hline
\end{tabular}

KL: Kraft Lignin; RL: Rye straw Lignin; AL: Alcell Lignin; SL: Soda Lignin: LS: Lignosulphonate.

B: batch system; SB: semi-batch system.

* Initial pressure at room temp erature.

*** Anthracene oil as solvent.

\# Batch unstirred. 


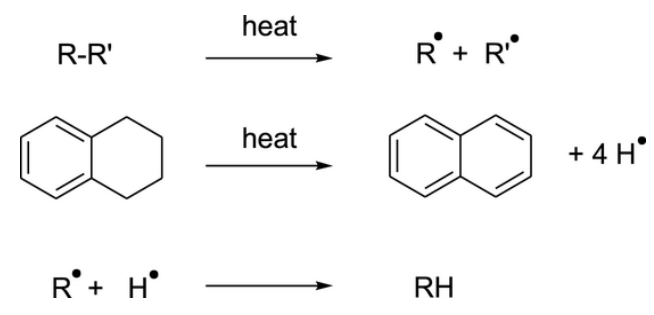

Scheme 8. Tetralin as a hydrogen-donor solvent to disable radical reactions.

light products and water in a cold trap and limited over-conversion of deoxygenated aromatics. The high efficiency of this system was confirmed by comparison with the previous one: the same conversion wa s reached in $5 \mathrm{~h}$ instead of $14 \mathrm{~h}$ of residence time, with the same extent of depolymerization and deoxygenation in the liquid. The catalytic conversion of a wheat straw soda lignin over $\mathrm{CoMoS} / \mathrm{Al}_{2} \mathrm{O}_{3}$ catalyst was performed followed by separation of the fractions and extensive characterizations of each. The evolution of depolymerization and hydrodeoxygenation products was clearly described with a total of $17 \%_{\mathrm{wt}}$ of monomers after $13 \mathrm{~h}$ of residence time. The experimental data obtained were used to build a kinetic model based on the Lump approach [90]. In comparison with other in situ hydrogen sources like alcohols and formic acid, tetralin reacted much less with lignin derivatives, limiting the difficulty of mass balance determination. How ever, in the previous studies, despite the advantages of using this hydrogen-donor solvent, many tetralin derivatives formed by methyl transfer from lignin were observed in low quantity, showing that tetralin was not only a kind hydrogen-donating specta tor solvent. In another work done with small unstirred batch reactors, temperatures higher than those used for coal liquefaction ( $>400{ }^{\circ} \mathrm{C}$ ) were employed for various lignin hydrogenolysis experiments over FeS/C catalyst, giving quite high liquid yields but also high quantities of gas [91]. A recent study was performed by Schneider et al. using anthracene oil as in coal hydroliquefaction industry [92]. Under high temperature and $\mathrm{H}_{2}$ pressure, with a low cost catalyst, FeSx, formed in situ and a continuous system to remove volatile products, the conversion of Kraft lignin (from grass or softwood) led to gases and deoxygenized oil, which was easily fractionated by solvent extraction.

\subsection{Catalysts}

As we have seen above, various types of heterogeneous catalysts have been reported in the literature, to reach high levels of liquefaction and monomer yields. These include monometallic, bimetallic and bifunctional catalysts. The efficient monometallic catalysts are generally expensive noble metal-based ones $\mathrm{Ru}, \mathrm{Rh}, \mathrm{Pd}$ and $\mathrm{Pt}$, supported on various carriers ( $\mathrm{C}, \mathrm{TiO}_{2}, \mathrm{Al}_{2} \mathrm{O}_{3}, \mathrm{SiO}_{2}, \mathrm{ZrO}_{2}$ ) or less expensive $\mathrm{Fe}$, Ni or $\mathrm{Cu}$ based solids. Besides the cost, many studies illustrated that noble metal catalysts demonstrate high hydrogenation activity, converting phenolic compounds into naphthenes and cyclohexanols, which is undesirable to preserve aromaticity and consume less hydrogen. On the contrary, the $\mathrm{Fe}$ and $\mathrm{Cu}$-based catalysts may have insufficient catalytic activity. However these catalysts have the advantage to be efficient under mild reaction conditions and can work without added $\mathrm{H}_{2}$ gas. In the case of bimetallic catalysts, a combination of metals corresponding to the ones used as conventional hydrotreating catalysts such as $\mathrm{Co}, \mathrm{Ni}$, Mo and W were widely studied, either as oxides or sulfides. By comparing the liquid yield, the sulfide catalysts exhibit better performance than the oxide ones. These well-known hydrotreating sulfide catalysts were origi-

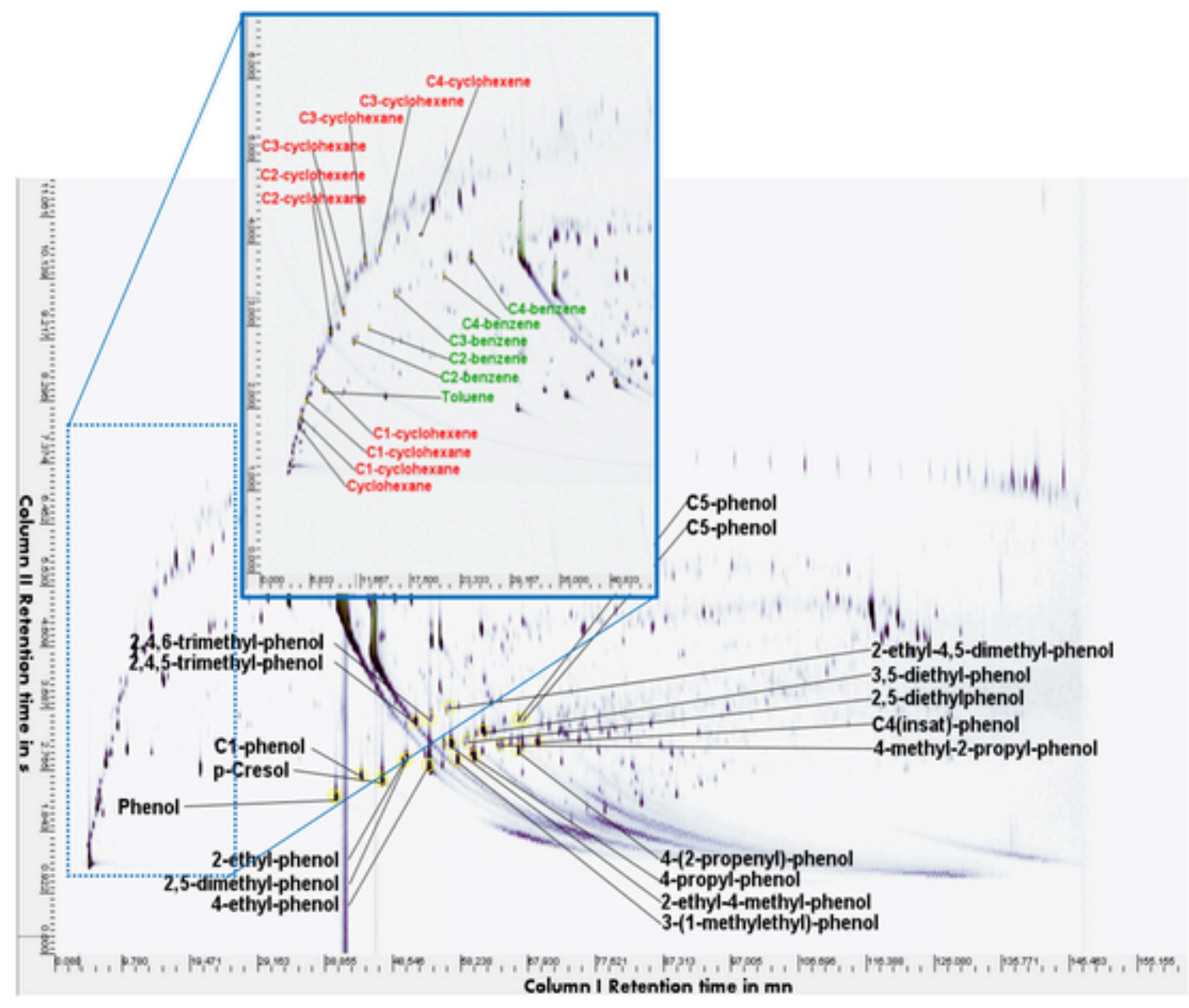

Fig. 3. GCxGC chromatogram of BTX, naphthenes and phenolic monomers with identification [86]. 
nally developed for the removal of sulfur (HDS) and nitrogen (HDN) for oil purification and upgrading processes. Therefore, they have been also tested for the removal of oxygen (HDO) from biomass-derived components, in co-processing with fossil oils. It was shown that with these catalysts, using model phenolic molecules such as guaiacol, HDO can be accomplished via two pathways: a direct deoxygenation of phenols to non-oxygenated aromatics or aromatic-ring saturation followed by a deoxygenation step $[93,94]$. The latter route is more favored at high pressures. More recently, a lot of works studied the lignin conversion using metal sulfide catalysts. It appears that when using sulfide catalysts, the yield of liquid was significantly higher than with other catalysts and the aromatic-ring saturation to cycloalkanes was limited.

Inspired by hydrocracking processes, bifunctional catalysts having both hydrogenation (Ni, Ru...) and cracking functions (SBA-15, AlSB A-15, HZSM-5...) were recently and successfully investigated [95]. The final products were usually alkanes and naphthenes, illustrating a highly active cracking activity. It is also claimed that the dehydration step was highly dependent on the acidity of the support.

\section{Conclusion}

From this concise literature overview on isolated lignin oxidative and reductive depolymerization, one can derive some conclusive comments.

Independently of the nature of the catalysts or that of the reaction media, it is clear that lignin conversion depends strongly on the nature of lignin and extraction methods. Thus, Organosolv extraction, known to keep more or less the original structure of the native lignin, delivers generally lignin more suitable for conducting depolymerization to monomeric aromatics and derived compounds. On the contrary, Kraft extraction, intensively performed in pulp industry, gives cross-linked lignin that is more refractory to depolymerization. Besides, the botanical origin plays also a main role on the structure and distribution of methoxyphenolic units.

Here, lignin extracted from hardwood presents syringyl moieties that are generally found to be more reactive toward oxidative depolymerization, delivering therefore higher yields of aromatics (mainly syringaldehyde), than those extracted from softwood and composed primarily of guaiacyl units. Nevertheless, for most studies, yields of aromatics remain relatively low, generally $10-20 \%_{\mathrm{wt}}$ in the best situations, even for total lignin conversion. This fact is intimately related to depolymerization methodology. Generally, over-oxidation of primary aromatic products is observed delivering linear (di)carboxylic acids, derived from aromatic ring opening together with oligomeric compounds. Within this approach, despite being in its infancy, the use of continuous flow processes can bring a credible answer to prevent over-oxidation of aromatic aldehydes. In some cases, the use of an alcoholic solvent (pure or as aqueous mixtures) helps to prevent such over-oxidation; however, while not systematically commented on, alcohols also contribute to the mass balance as aromatics observed result generally from their condensation with primary compounds forming alkylated products.

Interestingly, similar observation are made for the reductive depolymerization. Alcoholic solvents help to perform depolymerization under relative mild operating conditions, limiting recombinations even without gaseous $\mathrm{H}_{2}$ addition, but still reacting with the newly formed monomers. In this case, the yields of phenolic monomers can reach high values $(30 \%$ wt albeit in the presence of noble metal-based catalysts. Heavier hydrocarbon hydrogen-donor solvents were utilized, like tetralin, but these solvents require much more severe conditions especially under high $\mathrm{H}_{2}$ pressure. This leads to hydrodeoxygenation reactions and a portion of phenolic monomers is converted to BTX aromatics. However, in this case low cost catalysts can be employed. For solvent-free transformations, an even higher $\mathrm{H}_{2}$ pressure is needed, leading to good yields of liquid products despite significant formation of gaseous products.

Finally, by comparing depolymerization under oxidative and reductive conditions, one can say that obviously higher amount of monomers can be obtained under reductive atmosphere, even using low cost catalysts. On one hand, this confers a strong interest to this route. On the other hand, the target applications being very different, the market price of the obtained platform chemicals could be much lower than those obtained from oxidative depolymerization. In conclusion, despite issues and apparent limitations, the heterogeneously catalyzed oxidative and reductive lignin depolymerization remains an important area of research opening various opportunities of lignin valorization for the production of aromatic compounds from a non-edible biomass.

\section{Decl aration of Competing Interest}

The authors report no declarations of interest.

\section{Acknowledgements}

The authors thanks the French National Research Agency for funding through LIGNAROCAT (ANR-14-CE05-0039) and NANOTRAP (ANR-17-CE07-0027) projects.

\section{References}

[1] F. Gomes, R. de Souza, E. Brito, R. Lelis, L. Bathlha, F. Santos, D. J. Longue, A review on lignin sources and uses, J. Appl. Biotechnol. Bioeng. 7 (2020) $100-105$.

[2] J. Zakzeski, P.C.A. Bruijnincx, A.L. Jongerius, B.M. Weckhuys en, The catalytic valorization of lignin for the production of renewable chemicals, Chem. Rev. 110 (2010) 3552-3599.

[3] J.-M. Ha, K.-R. Hwang, Y.-M. Kim, J. Jae, K.H. Kim, H.W. Lee, J.-Y. Kim, Y. -K. Park, Recent progress in the thermal and catalytic conversion of lignin, Renew. Sus. En. Rev. 111 (2019) 422-441.

[4] C. Chio, M. Sain, W. Qin, Lignin utilization: a review of lignin depolymerization from various as pects, Renew. Sus. En. Rev. 107 (2019) 232-249.

[5] H. Wang, Y. Pu, A. Ragauskas, B. Yang, From lignin to valuable products Stra tegies, challenges, and prospects, Bior esour. Technol. Rep. 271 (2019) $449-461$.

[6] R. Xu, K. Zhang, P. Liu, H. Han, S. Zhao, A. Kakade, A. Khan, D. Du, X. Li, Lignin depolymerization and utilization by bacteria, Bioresour. Technol. Rep. 269 (2018) 557-566.

[7] A. Agarwal, M. Rana, J.-H. Park, Advancement in technologies for the depolymerization of lignin, Fuel Process. Technol. 181 (2018) 115-132.

[8] Z. Sun, B. Fridrich, A. de Santi, S. Elangovan, K. Barta, Bright side of lignin depolymerization: toward new platform chemicals, Chem. Rev. 118 (2018) 614-678.

[9] G.T. Beckham, C.W. Johnson, E.M. Karp, D. Salvachua, D.R. Vardon, Opportunities and challenges in biological lignin valorization, Curr. Opinion Biotechnol. 42 (2016) 40-53.

[10] R.E. Key, J.J. Bozell, Progress toward lignin valorization via selective catalytic technologies and the tailoring of biosynthetic pathways, ACS Sustain. Chem. Eng. 4 (2016) 5123-5135.

[11] S. Dutta, K. C. W. Wu, B. Saha, Emerging strategies for breaking the 3D am or phous network of lignin, Catal. Sci. Technol. 4 (2014) 3785-3799.

[12] R. Rinaldi, R. Jastrzebski, M.T. Clough, J. Ralph, M. Kennema, P.C.A. Bruijnincx, B.M. Weckhuysen, Paving the way for lignin valorisation: recent advances in bioengineering, biorefining and catalysis, Angew. Chem. Int. Ed. 55 (2016) 8164-8215.

[13] S. Van den Bosch, S. F. Koelewijn, T. Renders, G. Van den Boss che, T. Vangeel, W. Schutyser, B.F. Sels, Ca taly tic stra tegies towards lignin-derived chemicals, Top. Curr. Chem. J. (J) 376 (2018) 36.

[14] W. Schutyser, T. Renders, S. Van den Bosch, S. F. Koelewijn, G.T. Beckham, B. F. Sels, Chemicals from lignin: an interplay of lignocellulose fractionation, depolymerisation, and upgrading, Chem. Soc. Rev. 47 (2018) 852-908.

[15] C. Liu, S. Wu, H. Zhang, R. Xiao, Catalytic oxidation of lignin to valuable biomass-based platform chemicals: a review, Fuel Process. Technol. 191 (2019) 181-201.

[16] R. Ma, M. Guo, X. Zhang, Recent advances in oxidative valorization of lignin, Catal. Today 302 (2018) 50-60.

[17] W. Schutyser, J.S. Kruger, A.M. Robinson, R. Katahira, D.G. Brandner, N.S. Cleveland, A. Mittal, D.J. Peters on, R. Meilan, Y. Roman-Leshkov, G.T. Beckham, Revisiting alkaline aerobic lignin oxidation, Green Chem. 20 (2018) 3828-3844.

[18] T. Vangeel, W. Schutyser, T. Renders, B.F. Sels, Pers pective on lignin oxidation: advances, chal lenges, and future directions, Top. Curr. Chem. 376 
(2018) 1-16.

[19] V.E. Tarabanko, N. Tarabanko, Catalytic oxidation of lignins into the aromatic aldehydes: general process trends and development prospects, Int J. Mol. Sci. 18 (2017) 2421.

[20] C. Cheng, J. Wang, D. Shen, J. Xue, S. Guan, S. Gu, K.H. Luo, Catalytic oxidation of lignin in solvent systems for production of renewable chemicals: a review, Polymers 9 (2017) 240.

[21] R. Behling, S. Valange, G. Chatel, Heterogeneous catalytic oxidation for lignin valorization into valuable chemicals: What results? What limitations? What trends?, Green Chem. 18 (2016) 1839-1854.

[22] J. Dai, A.F. Patti, K. Saito, Recent developments in chemical degradation of lignin: catalytic oxidation and ionic liquids, Tetrahedron Lett. 57 (2016) 4945-4951.

[23] S. K. Hanson, R.T. Baker, Knocking on wood: base metal complexes as catalysts for selective oxidation of lignin models and extracts, Acc. Chem. Res. 48 (2015) 2037-2048.

[24] R. Ma, Y. Xu, X. Zhang, Catalytic oxidation of biorefinery lignin to valueadded chemicals to support sustainable biofuel production, ChemSusChem 8 (2015) 24-51.

[25] G. Chatel, R.D. Rogers, Review: oxidation of lignin using ionic liquids - an innovative strategy to produce renewable chemicals, ACS Sustain. Chem. Eng. 2 (2014) 322-339.

[26] H. Lange, S. Decina, C. Crestini, Oxidative upgrade of lignin - recent routes reviewed, Eur. Polym. J. 49 (2013) 1151-1173.

[27] C. Crestini, M. Crucianelli, M. Or landi, R. Saladino, Oxidative strategies in lignin chemistry: a new environmental friendly approach for the functional is ation of lignin and lignocellulosic fibers, Ca tal. Today 156 (2010) 8-22.

[28] T. Voitl, P.R. von Rohr, Demonstration of a process for the conversion of kraft lignin into vanillin and methyl va nillate by acidic oxidation in aqueous methanol, Ind. Eng. Chem. Res. 49 (2010) 520-525.

[29] Y. Zhao, Q. Xu, T. Pan, Y. Zuo, Y. Fu, Q. -X. Guo, Depolymerization of lignin by catalytic oxidation with aqueous polyoxometalates, Appl. Catal. A Gen. 467 (2013) 504-508.

[30] W. Sebhat, A. El-Roz, A. Crepet, C. La daviere, D.D.S. Perez, S. Mangematin, C. C. Alma da, L. Vilcocq, L. Djakovitch, P. Fongar land, Comparative study of solvolys is of technical lignins in flow reactor, Biomas s Conv. Bioref. 10 (2020) 351-366.

[31] B.N. Kuznetsov, N.V. Chesnokov, I.G. Sudakova, N.V. Garyntseva, S. A Kuznetsova, Y.N. Malyar, V.A. Yakovlev, L. Djakovitch, Green cataly tic processing of native and organosolv lignins, Catal. Today 309 (2018) 18-30.

[32] A.G. Demesa, A. Laari, M. Sillanpaa, T. Koiranen, Valorization of lignin by partial wet oxidation using sustainable heteropoly acid catalysts, Molecules 22 (2017) 1625.

[33] J. Zhang, H. Deng, L. Lin, Wet aerobic oxidation of lignin into aromatic aldehydes catalyzed by a Perovskite-type oxide: $\mathrm{LaFe}_{1-\mathrm{x}} \mathrm{Cu}_{\mathrm{x}} \mathrm{O}_{3}(\mathrm{x}=0,0.1,0$. 2), Molecules 14 (2009) 2747-2757.

[34] H. Deng, L. Lin, Y. Sun, C. Pang, J. Zhuang, P. Ouyang, J. Li, S. Liu, Activity and stability of perovskite-type oxide $\mathrm{LaCoO}_{3}$ catalyst in lignin cataly tic wet oxidation to aromatic aldehydes process, Energy Fuels 23 (2009) 19-24.

[35] H. Deng, L. Lin, Y. Sun, C. Pang, J. Zhuang, P. Ouyang, Z. Li, S. Liu, Perovskite-type oxide $\mathrm{La} \mathrm{MnO}_{3}$ : an efficient and recyclable heterogeneous catalyst for the wet aerobic oxidation of lignin to aromatic aldehydes, Catal. Lett. 126 (2008) 106-111.

[36] M. Yang, A. Xu, H. Du, C. Sun, C. Li, Removal of salicylic acid on perovskite-type oxide $\mathrm{LaFeO}_{3}$ catalyst in cataly tic wet air oxidation process, J. Ha zard. Mater. 139 (2007) 86-92.

[37] S. Royer, B. Levass eur, H. Alam dari, J. Barbier, D. Duprez, S. Kaliag uine, Mechanism of stearic acid oxidation over nanocrystalline $\mathrm{La}_{1-\mathrm{x}} \mathrm{A}_{\mathrm{x}}^{\prime} \mathrm{BO}_{3}\left(\mathrm{~A}^{\prime}=\right.$ $\mathrm{Sr}, \mathrm{Ce} ; \mathrm{B}=\mathrm{Co}, \mathrm{Mn}$ ): the role of oxygen mobility, Appl. Catal. B 80 (2008) $51-61$.

[38] C. Crestini, M.C. Caponi, D.S. Argyropoulos, R. Sala dino, Immobilized methyltrioxo rhenium (MTO) $/ \mathrm{H}_{2} \mathrm{O}_{2}$ systems for the oxidation of lignin and lignin model compounds, Bioorg. Med. Chem. 14 (2006) 5292-5302.

[39] J.C. Villar, A. Caperos, F. Garcia-Ochoa, Oxidation of hardwood kraftlignin to phenolic derivatives with oxygen as oxidant, Wood Sci. Technol. 35 (2001) 245-255.

[40] J. Luo, P. Melissa, W. Zhao, Z. Wang, Y. Zhu, Selective lignin oxidation towards va nillin in phenol media, Chem. Select 1 (2016) 4596-4601.

[41] L. Hdidou, L. Kouisni, B. Manoun, H. Hannache, A. Solhy, A. Barakat, Oxidative conversion of lignin over cobalt-iron mixed oxides prepared via the alginate gelation, Catal. Comm un. 117 (2018) 99-104.

[42] L. Hdidou, K. Khallouk, A. Solhy, B. Manoun, A. Oukarroum, A. Barakat, Synthesis of $\mathrm{CoFeO}$ mixed oxides via an alginate gelation process as efficient heterogeneous catalysts for lignin depolymerization in water, Catal. Sci. Technol. 8 (2018) 5445-5453.

[43] K. Sun, S. Chen, J. Zhang, G.-P. Lu, C. Cai, Cobalt nanoparticles embedded in $\mathrm{N}$-doped porous carbon derived from bimetallic zeolitic imidazolate fram eworks for one-pot selective oxidative depolymerization of lignin, Chem Ca tChem 11 (2019) 1264-1271.

[44] Y. Song, J.K. Mobley, A.H. Motagamwala, M. Isaacs, J.A. Dumesic, J. Ralph, A.F. Lee, K. Wils on, M. Crocker, Gold-catalyzed conversion of lignin to low molecular weight arom atics, Chem. Sci. 9 (2018) 8127-8133.

[45] W. Deng, H. Zhang, X. Wu, R. Li, Q. Zhang, Y. Wang, Oxidative conversion of lignin and lignin model compounds catalyzed by $\mathrm{CeO}_{2}$-supported Pd nanoparticles, Green Chem. 17 (2015) 5009-5018.
[46] F.G. Sales, L.C.A. Maranhao, N.M. Lima Filho, C.A.M. Abreu, Experimental evaluation and continuous cataly tic process for fine aldehyde production from lignin, Chem. Eng. Sci. 62 (2007) 5386-5391.

[47] F.G. Sales, L. C.A. Maranhao, N.M. Lima Filho, C.A.M. Abreu, Kinetic evaluation and modeling of lignin catalytic wet oxidation to selective production of aromatic aldehydes, Ind. Eng. Chem. Res. 45 (2006) $6627-6631$.

[48] F.G. Sales, C.A.M. Abreu, J.A.F.R. Pereira, Catalytic wet-air oxidation of lignin in a three-phase reactor with aromatic aldehyde production, Braz. J. Chem. Eng. 21 (2004) 211-218.

[49] H. R. Muddas sa r, M.H. Sipponen, K. Melin, D. de Kokkonen, O. Pastinen, S. Golam, Effects of catalysts and pH on lignin in partial wet oxidation of wood and straw black liquors, Ind. Eng. Chem. Res. 54 (2015) 7833-7840.

[50] P. Tomani, The lignoboost process, Cellulose Chem. Technol. 44 (2010) 53-58.

[51] B. Valle, A.G. Gayubo, A.T. Aguayo, M. Olazar, J. Bilbao, Selective production of aromatics by crude bio-oil valorization with a nickel-modified HZSM-5 zeolite catalyst, Energy Fuels 24 (2010) 2060-2070.

[52] S. Lotfi, D.C. Boffito, G.S. Patience, Gas-phas e partial oxidation of lignin to carboxylic acids over va nadium pyrophos phate and al uminum-vanadiummolybdenum, ChemSusChem 8 (2015) 3424-3432.

[53] S. Lotfi, D.C. Boffito, G.S. Patience, Gas-solid conversion of lignin to carboxylic acids, React. Chem. Eng. 1 (2016) 397-408.

[54] X.-F. Zhou, X.-J. Lu, Co (salen) supported on graphene oxide for oxidation of lignin, J. Appl. Polym. Sci. 133 (2016).

[55] L. Zhao, S. Shi, M. Liu, G. Zhu, M. Wang, W. Du, J. Gao, J. Xu, Covalent triazine fram ework cataly tic oxidative cleavage of lignin models and organosolv lignin, Green Chem. 20 (2018) 1270-1279.

[56] C.S. Lancefield, O.S. Oj o, F. Tran, N.J. Westwood, Isolation of functionalized phenolic monomers through selective oxidation and C-O bond cleava ge of the $\beta$-O-4 linkages in lignin, Angew. Chem. Int. Ed. 54 (2015) 258-262.

[57] E.E. Harris, J. D'Ianni, H. Adkins, Reaction of hardwood lignin with hydrog en, J. Am. Chem. Soc. 60 (1938) 1467-1470.

[58] J.M. Pepper, H. Hibbert, Studies on lignin and related compounds. LXXXVII. High pressure hydrogenation of maple Wood, J. Am. Chem. Soc. 70 (1948) $67-71$

[59] M. A. Ratcliff, D.K. Johnson, F.L. Posey, H.L. Chum, Hydrodeoxy genation of lignins and model compounds, Appl. Biochem. Biotechnol. 17 (1988) $151-160$.

[60] D. Meier, R. Ante, O. Faix, Catalytic hydropyrolys is of lignin: influence of reaction conditions on the formation and composition of liquid products, Bior esour. Technol. Rep. 40 (1992) 171-177.

[61] A. Oasmaa, R. Alén, D. Meier, Catalytic hydrotreatment of some technical lignins, Bior esour. Technol. Rep. 45 (1993) 189-194.

[62] A. Kloekhorst, H.J. Heeres, Ca taly tic hydrotreatment of Alcell lignin using supported Ru, Pd, and Cu catalysts, ACS Sustain. Chem. Eng. 3 (2015) 1905-1914.

[63] C. R. Kuma r, N. Anand, A. Kloekhorst, C. Cannilla, G. Bonura, F. Frusteri, K. Barta, H. J. Heeres, Solvent free depolymerization of Kraft lignin to alkylphenolics using supported NiMo and CoMo catalysts, Green Chem. 17 (2015) 4921-4930.

[64] A. Kloekhorst, J. Wild schut, H.J. Heeres, Ca taly tic hydrotreatment of pyrolytic lignins to give alkylphenolics and aromatics using a supported Ru catalyst, Ca tal. Sci. Technol. 4 (2014) 2367-2377.

[65] S. Agarwal, R.K. Chowdari, I. Hita, H.J. Heeres, Experimental studies on the hydrotreatment of Kraft lignin to aromatics and al kylphenolics using economically viable Fe-based catalysts, ACS Sustain. Chem. Eng. 5 (2017) 2668-2678.

[66] R.K. Chowdari, S. Agarwal, H. J. Heeres, Hydrotreatment of Kraft lignin to alkylphenolics and aromatics using Ni, Mo, and W phosphides supported on activated carbon, ACS Sustain. Chem. Eng. 7 (2019) 2044-2055.

[67] J. Horáček, F. Homola, I. Kubičková, D. Kubička, Lignin to liquids over sulfided catalysts, Ca tal. Today 179 (2012) 191-198.

[68] B. Joffres, C. Lorentz, M. Vidalie, D. La urenti, A.A. Quoineaud, N. Charon, A. Daudin, A. Quignard, C. Geantet, Ca talytic hydroconversion of a wheat straw soda lignin: characterization of the products and the lignin residue, Appl. Ca tal. B: Env. 145 (2014) 167-176.

[69] P. de Wild, R. Van der Laan, A. Kloekhorst, E. Heeres, Lignin valorisation for chemicals and (transportation) fuels via (catalytic) pyrolysis and hydrodeoxy genation, Env. Progr. Sus. Energy 28 (2009) 461-469.

[70] J. Kong, M. He, J.A. Lercher, C. Zhao, Direct production of naphthenes and paraffins from lignin, Chem. Comm un. (Cam b.) 51 (2015) 17580-17583.

[71] N.P. Vasilakos, D.M. Austgen, Hy drogen-donor solvents in biomas s liquefaction, Ind. Eng. Chem. Process Des. Dev. 24 (1985) 304-311.

[72] J.O. Strüven, D. Meier, Hydrocracking of organosolv lignin in subcritical water to useful phenols employing various Raney nickel catalysts, ACS Sustain. Chem. Eng. 4 (2016) 3712-3721.

[73] Y. Ye, Y. Zhang, J. Fan, J. Chang, Selective production of 4-ethylphenolics from lignin via mild hydrog enolys is, Bior esour. Technol. Rep. 118 (2012) 648-651.

[74] X. Zhang, Q. Zhang, J. Long, Y. Xu, T. Wang, L. Ma, Y. Li, Phenolics production through catalytic depolymerization of alkali lignin with metal chlorides, BioRes. 9 (2014) 3347-3360.

[75] X. Huang, T.I. Korányi, M. D. Boot, E.J.M. Hensen, Ca taly tic depolymerization of lignin in supercritical ethanol, ChemSusChem 7 (2014) 2276-2288. 
[76] M. Or egui-Bengoechea, I. Gandarias, P.L. Arias, T. Barth, Unra veling the role of form ic acid and the type of solvent in the catalytic conversion of lignin: a holistic approach, ChemSusChem 10 (2017) 754-766.

[77] T. Li, H. Lin, X. Ouyang, X. Qiu, Z. Wan, In situ preparation of Ru@N-doped carbon catalyst for the hydrog enolys is of lignin to produce aromatic monomers, ACS Catal. 9 (2019) 5828-5836.

[78] K. Barta, G.R. Warner, E.S. Beach, P.T. Anastas, Depolymerization of organosolv lignin to aromatic compounds over Cu-doped porous metal oxides, Green Chem. 16 (2014) 191-196.

[79] Z. Tang, Y. Zhang, Q. Guo, Ca taly tic hydrocracking of pyroly tic lignin to liquid fuel in supercritical ethanol, Ind. Eng. Chem. Res. 49 (2010) 2040-2046.

[80] X. Huang, T.I. Korányi, M.D. Boot, E.J.M. Hensen, Ethanol as capping ag ent and form aldehyde scavenger for efficient depolymerization of lignin to aromatics, Green Chem. 17 (2015) 4941-4950.

[81] L. Kong, C. Liu, J. Gao, Y. Wang, L. Dai, Efficient and controllable al coholysis of Kraft lignin catalyzed by porous zeolite-supported nickelcopper catalyst, Bior esour. Technol. Rep. 276 (2019) 310-317.

[82] J. Hu, S. Zhang, R. Xiao, X. Jiang, Y. Wang, Y. Sun, P. Lu, Ca taly tic tran sfer hydrog enolys is of lignin in to monophenols over platinum-rhenium supported on titanium dioxide using isopropanol as in situ hydrogen source, Bior esour. Technol. Rep. 279 (2019) 228-233.

[83] T. Kleinert, Hydrogenation of lignin with cyclohexanol, Monatsh. Chem. 83 (1952) 623-628,

[84] W.J. Connors, L. N. Johanson, K.V. Sarkanen, P. Winslow, Thermal degradation of Kraft lignin in tetral in, Holzfors chung 34 (1980) 29-37.

[85] B. Klopries, W. Hodek, F. Bandermann, Ca taly tic hydroliquefaction of biomas s with red mud and $\mathrm{CoO}-\mathrm{MoO}_{3}$ catalysts, Fuel 69 (1990) 448-455.

[86] R.W. Thring, J. Breau, Hydrocracking of solvolys is lignin in a batch reactor, Fuel 75 (1996) 795-800.

[87] K.H. Kim, R.C. Brown, M. Kieffer, X. Bai, Hydrogen-donor-as sisted solvent liquefaction of lignin to short-chain alkylphenols using a micro reactor/gas chro ma tography system, Energy Fuels 28 (2014) 6429-6437.

[88] B. Joffres, M. T. Nguyen, D. Laurenti, C. Lorentz, V. Souchon, N. Charon, A. Daudin, A. Quignard, C. Geantet, Lignin hydroconversion on $\mathrm{MoS}_{2}$-based supported catalyst: comprehensive analys is of products and reaction scheme, Appl. Ca tal. B: Env. 184 (2016) 153-162.

[89] J. Pu, T.-S. Nguyen, E. Leclerc, C. Lorentz, D. La urenti, I. Pitault, M. Taya kout-Fayolle, C. Geantet, Lignin cataly tic hydroconversion in a semicontinuous reactor: an experimental study, Appl. Catal. B 256 (2019) 117769.

[90] J. Pu, D. La urenti, C. Geantet, M. Tayakout-Fayolle, I. Pitault, Kinetic modeling of lignin catalytic hydroconversion in a semi-batch reactor, Chem. Eng. J. 386 (2020) 122067.

[91] M. Breunig, P. Gebhart, U. Hornung, A. Kruse, E. Dinjus, Direct liquefaction of lignin and lignin rich biomas ses by heterogenic cataly tic hydrogenolys is, Biomas s Bioenergy 111 (2018) 352-360.

[92] I. Schneider, K. Kebelmann, S. Risse, A. Dieguez-Alonso, B. Schartel, C. Strecker, F. Behrendt, Hydroliquefaction of two Kraft lignins in a semibatch setup under process conditions applicable for larg e-scale biofuel production, Energy Fuels 33 (2019) 11057-11066.

[93] V.N. Bui, D. La urenti, P. Afanas iev, C. Geantet, Hy drodeoxy genation of guaiacol with CoMo catalysts. Part I: promoting effect of cobalt on HDO selectivity and activity, Appl. Catal. B: Env. 101 (2011) 239-245.

[94] V.N. Bui, D. Laurenti, P. Delichère, C. Geantet, Hy drodeoxy genation of guaiacol: part II: support effect for CoMoS catalysts on HDO activity and selectivity, App. Ca tal. B: Env. 101 (2011) 246-255.

[95] X. Wang, R. Rinaldi, Bifunctional Ni catalysts for the one-pot conversion of Organosolv lignin into cycloalkanes, Ca tal. Today 269 (2016) 48-55. 